\title{
Morfologia externa do adulto de Actinote melanisans (Nymphalidae: Heliconiinae: Acraeini) ${ }^{1}$
}

\author{
Márlon Paluch 2, 4; Mirna M. Casagrande ${ }^{3,4} \&$ Olaf H. H. Mielke ${ }^{3,4}$
}

\author{
1 Contribuição 1666 do Departamento de Zoologia, Universidade Federal do Paraná. \\ ${ }^{2}$ Departamento de Zoologia, Universidade Federal de Pernambuco. Avenida Professor Moraes Rêgo, Cidade Universitária, \\ 50670-901 Recife, Pernambuco, Brasil. E-mail: marlonpaluch@gmail.com \\ 3 Laboratório de Estudos de Lepidoptera Neotropical, Departamento de Zoologia, Universidade Federal do Paraná. \\ Caixa Postal 19020,81531-980 Curitiba, Paraná, Brasil.E-mail: mibras@ufpr.br; omhesp@ufpr.br \\ 4 Pesquisador do CNPq.
}

\begin{abstract}
External morphology of adult A. melanisans (Nymphalidae: Heliconiinae: Acraeini). The external morphology of adult $A$. melanisans Oberthür, 1917 is described and illustrated. The results obtained were compared with other studies already published on the external morphology of Nymphalidae - Danainae: Brassolinae: Brassolini sensu CASAGRANDE (2004), Morphinae: Morphini sensu Lamas (2004a), Ithomiinae and Charaxinae. A pattern for the morphological characterization of the genus is presented. It is the first detailed study of the morphology of a species of Acraeini, therefore contributing with information on characters useful for the phylogenetic analysis of the Neotropical species.
\end{abstract}

KEY WORDS. Acraeini; Actinote; butterfly; morphology; Neotropical.

RESUMO. A morfologia externa do adulto de A. melanisans Oberthür, 1917 é descrita e ilustrada. Os resultados obtidos foram comparados com outros já publicados para a morfologia externa de Nymphalidae (Danainae, Brassolinae/Brassolini sensu CAsagrande (2004), Morphinae/Morphini sensu Lamas (2004a), Ithomiinae e Charaxinae). É apresentado um padrão para a caracterização morfológica do gênero, sendo esse o primeiro estudo detalhado de morfologia de uma espécie de Acraeini, agregando informações úteis para subsidiar a análise filogenética das espécies Neotropicais.

PALAVRAS-CHAVE. Acraeini; Actinote; borboleta; morfologia; Neotropical.

Acraeini (Heliconiinae), até recentemente, incluía sete gêneros: Acraea Fabricius, 1807; Pardopsis Trimen, 1887; Miyana Fruhstorfer, [1914] e Bematistes Hemming, 1935 (= Planema Doubleday, 1848) com espécies distribuídas na região Paleotropical, e Actinote Hübner, [1819], Abananote Potts, 1943 e Altinote Potts, 1943 com distribuição Neotropical (VAN SON 1963, Ackery 1984, 1988, Penz \& Francini 1996, Penz \& Peggie 2003, Lamas 2004b, Francini et al. 2004, Silva-Brandão et al. 2008).

Pierre (1985a,b,c, 1986) realizou estudos morfológicos de Acraeini envolvendo análise das garras tarsais, tampão genital, glândula subpapilar e genitálias masculina e feminina principalmente das espécies Paleotropicais. A reunião destes trabalhos culminou na primeira hipótese filogenética da tribo. Nesta proposta, Pierre (1987) apresentou apenas Acraea (incluindo Bematistes), como um táxon parafilético com dois clados (subgêneros). Para este autor, o subgênero Acraea (Actinote) incluiria todas as espécies de Acraeini Neotropicais e, ainda, muitos grupos de espécies africanas, os "Actinote do Velho Mundo". Pardopsis foi considerado como um plausível grupo irmão de Acraea.
Contudo, Pierre (1987) não mencionou caracteres das espécies de Abananote e Altinote, nem a possibilidade destes formarem juntamente com Actinote, três grupos distintos dentro de Acraea (Actinote), caso comprovada a monofilia dessas linhagens (Lamas 1996).

Recentemente, SiLVA-BRANDão et al. (2008) publicaram uma hipótese filogenética para Acraeini baseada em dados moleculares de três genes: "cytochrome oxidase I", "elongation factor $1 \alpha$ " e "wingless". Os resultados relacionaram Pardopsis com os Argynnini, portanto, fora do grupo Acraeini. A posição de Miyana não pôde ser definida. E dentro do foco principal do trabalho, Acraea sensu stricto (incluindo Bematistes) foi definido como parafilético sendo que o nível genérico deve ser utilizado temporariamente principalmente pelas Acraea - Africana que se alimentam de Passifloraceae, até que novas amostragens possam definir os grupos naturais. O clado dos "Actinote do Velho Mundo" é monofilético e grupo irmão de todas as espécies Neotropicais. Nesse grupo, pode ser revalidado o gênero Telchinia Hübner, [1819] (espécie tipo: Papilio serena Fabricius, 1775). Se- 
gundo os autores, Actinote sensu stricto deveria ser ampliado para incluir todos os Acraeini Neotropicais. Dentro do clado Neotropical, três grupos foram bem definidos: 1) Altinote eresia (C. Felder \& R. Felder, 1862) emergiu como um táxon basal irmão de todas as espécies Neotropicais, 2) um clado de espécies andinas envolvendo Altinote e Abananote (ambos polifiléticos) e, 3) o clado de Actinote (s. str.) monofilético.

Visando a caracterização morfológica dos adultos de Actinote, A. melanisans Oberthür, 1917, uma espécie bastante freqüente no sul do Brasil, foi utilizada para estudar e ilustrar os caracteres morfológicos em função das espécies apresentarem baixa variação interespecífica nas estruturas e apêndices da cabeça, tórax e abdome.

Sempre que possível, os dados foram comparados com os encontrados na literatura para os Acraeini Neotropicais, com intuito de adicionar novos caracteres morfológicos que possam ser utilizados na filogenia das espécies. Objetivando melhor entender a plasticidade de alguns caracteres são feitas comparações com espécies de outras subfamílias, tais como Danainae (Ehrlich 1958a, b), Brassolinae (CASAgrande 1979a, b, c), Morphinae (BilotTa 1992, 1994a, b), Ithomiinae (Bizarro et al. 2003a, b, c) e Charaxinae (C. Mielke et al. 2004a, b, c).

\section{MATERIAL E MÉTODOS}

Os adultos de A. melanisans (Figs 1-4) foram obtidos a partir de criações em cativeiro de imaturos coletados em três municípios adjacentes no estado do Paraná, nos parques de Curitiba

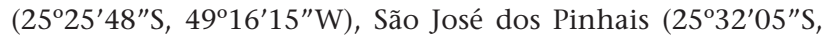

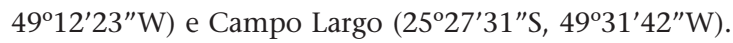

Após a emergência dos adultos, esperou-se de três a quatro dias para que as estruturas atingissem o grau de esclerotinização adequada (C. MielKe et al. 2004a).

Os exemplares utilizados para os estudos morfológicos foram sacrificados em vidro letal contendo acetato de etila e preservados a seco em envelopes entomológicos. Os demais foram preparados e incluídos na Coleção Entomológica Padre Jesus Santiago Moure, Departamento de Zoologia, Universidade Federal do Paraná.

Nos estudos morfológicos, após a remoção das asas, foram dissecados cabeça, tórax e abdome pelo método de fervura em $\mathrm{KOH}$ a $10 \%$, em banho-maria, por aproximadamente cinco minutos, a partir do ponto de ebulição, para amolecimento e clarificação. Preparou-se vários exemplares de ambos os sexos na avaliação de dimorfismo sexual.

$\mathrm{O}$ reconhecimento das estruturas e os desenhos foram feitos em microscópio estereoscópico Zeiss STEMI SV6 com câmara clara acoplada. As medidas foram obtidas mediante o uso de ocular micrométrica ou diretamente nos desenhos. Excetuando-se a escala do esclerito cervical que é de $0,1 \mathrm{~mm}$, as demais representam $1 \mathrm{~mm}$.

Para análise da venação alar, as asas foram destacadas do tórax e submetidas ao protocolo usual de clarificação (BizARro et al. 2003b). Para as análises de microscopia eletrônica de var- redura (MEV), foi utilizado material fixado em álcool a 70\% de acordo com o protocolo citado por DUARTE et al. (2001).

Os termos empregados na interpretação da morfologia dos adultos são aqueles já utilizados em publicações para Nymphalidae: Danainae (Ehrlich 1958a, b), Brassolinae (Casagrande 1979a, b, c), Morphinae (Bilotta 1992, 1994 a, b) Ithomiinae (Bizarro et al. 2003a, b, c) e Charaxinae (C. Mielke et al. 2004a, b, c).

Para levantamento de caracteres filogeneticamente informativos, foi estabelecida uma comparação com as demais espécies do gênero representadas no acervo da Coleção Entomológica Padre Jesus Santiago Moure; para comparações entre as estruturas das genitálias masculinas, utilizou-se a chave ilustrada para machos de Actinote do sudeste do Brasil de Francini \& Penz (2006), além das ilustrações das espécies novas descritas por PAluch et al. (2006). As seguintes espécies e subespécies foram analisadas: A. alalia (C. Felder \& R. Felder, 1860); A. bonita Penz, 1996; A. canutia (Hopffer, 1874); A. carycina Jordan, 1913; A. catarina Penz, 1996; A. conspicua Jordan, 1913; A. dalmeidai Francini, 1996; A. discrepans D’Almeida, 1958; A. eberti Francini, Freitas \& Penz, 2004; A. furtadoi Paluch, Casagrande \& Mielke, 2006; A. genitrix D'Almeida, 1922; A. mamita mitama (Schaus,1902); A. melampeplos Godman \& Salvin, 1881; A. mielkei Paluch \& Casagrande, 2006; A. mirnae Paluch \& Mielke, 2006; A. morio morio Oberthür, 1917; A. morio beckeri Paluch, Casagrande \& Mielke, 2006; A. parapheles Jordan, 1913; A. pellenea pellenea Hübner, [1821]; A. pellenea giffordi Paluch, Casagrande \& Mielke, 2006; A. pyrrha pyrrha (Fabricius, 1775); A. quadra (Schaus, 1902); A. rhodope D Almeida, 1923; A. surima surima (Schaus, 1902); A. thalia anteas (Doubleday, [1847]); A. thalia brettia Oberthür, 1917; A. thalia crassinia (Hoppfer, 1874); A. thalia eupelia Jordan, 1913; A. thalia suspecta Jordan, 1913; A. zikani D'Almeida, 1951.

\section{RESULTADOS}

\section{Cabeça (Figs 5-24)}

Hipognata, castanho-enegrecida com escamas amarelas no frontoclípeo; mais larga do que longa; desprovida de ocelos; com as seguintes medidas: largura média 2,8 mm; distância média entre a base dos olhos compostos, na porção mediana do frontoclípeo e logo acima das fóveas tentoriais anteriores 1,1 mm; altura média do olho medida na base $1,5 \mathrm{~mm}$; distância média entre as suturas transfrontal e clipeolabral 0,9 mm.

Em vista anterior, os olhos compostos são castanho-avermelhados, glabros e globulares, com margem ocular reta, são formados por omatídios hexagonais com ausência de cerdas interomatidiais (Figs 6 e 13). Área central anterior ocupada pelo frontoclípeo proeminente e retangular, recoberto por escamas e cerdas (Fig. 10), limitado superiormente pela sutura transfrontal curta entre os alvéolos antenais. O limite inferior é feito pela faixa transclipeal esclerotinizada, nitidamente separada do frontoclípeo por não apresentar a inserção de cerdas e escamas, além de ser formada por uma depressão em degrau. 


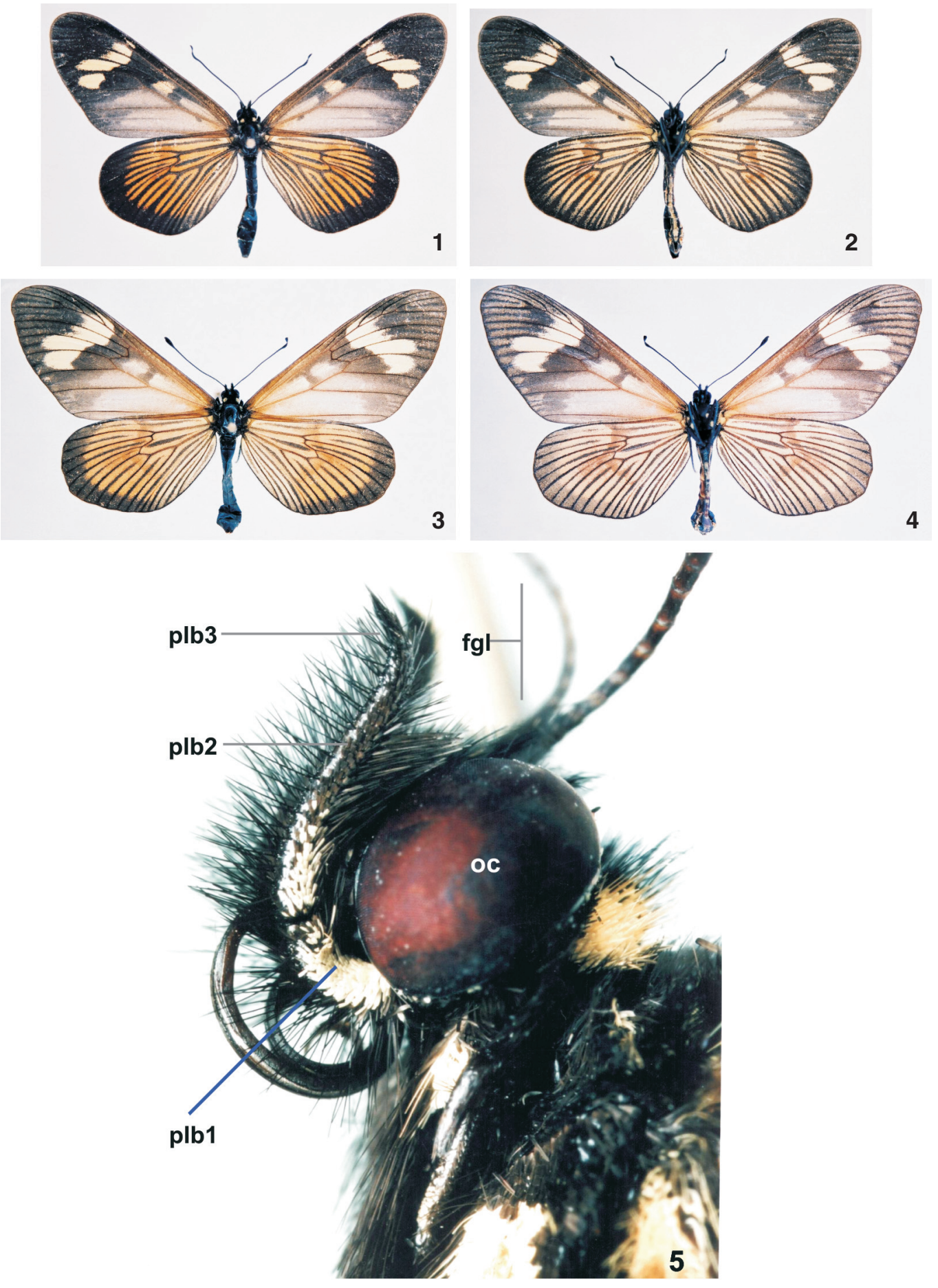

Figuras 1-5. Actinote melanisans: (1) macho, vista dorsal; (2) macho, vista ventral; (3) fêmea, vista dorsal; (4) fêmea, vista ventral; (5) macho, vista lateral da cabeça. (fgl) Flagelo antenal, (oc) olho composto, (plb1) artículo basal do palpo labial, (plb2) artículo mediano do palpo labial, (plb3) artículo distal do palpo labial.

Revista Brasileira de Zoologia 25 (3): 456-478, September, 2008 
Nas áreas perpendiculares ao limite superior da faixa transclipeal, na sutura subgenal, estão localizadas as fóveas tentoriais anteriores, marcadas por uma invaginação do exoesqueleto (SNODGRass 1935) (Figs 10-13).

Lateralmente, o frontoclípeo é limitado pela sutura láterofacial sensu EHrLich (1858a), que acompanha a margem ocular, delimitando a área paraocular. Em $A$. melanisans esta área consiste de uma faixa reta sem curvas e relativamente larga. Entre a fóvea tentorial anterior e a sutura látero-facial, a área subgenal apresenta-se similar a um triângulo isósceles, de base côncava próxima ao pilífero. Rudimento mandibular cônico, ornamentado pela presença microscópica de ornamentações pontiagudas no tegumento, cerdas internas próximas ao labro e um grupo de escamas retangulares externas, aproximadamente sete, próximas à sutura látero-facial (Figs 6, 10 e 12).

Em vista dorsal, nota-se a proeminência do frontoclípeo; a sutura transfrontal curta, situada em uma leve depressão entre os alvéolos antenais, delimita o frontoclípeo do vértice, este é bilobado e bem acentuado formando uma projeção posterior quadrangular (Fig. 7). Quetosema, assim como em Thyridia psidii cetoides (Rosenberg \& Talbot, 1914), Agrias claudina annetta (Gray, 1832) e Zaretis itys itylus (Westwood, 1850) (BIzARro et al. 2003a, C. MielKe et al. 2004a), está presente em A. melanisans, é reniforme, localizado látero-posteriormente aos alvéolos antenais e estendendo-se para a projeção posterior do vértice, pelo occipício, até a sutura pós-occipital que delimita o esclerito pós-occipital (Fig. 9).

Ventralmente, entre as áreas subgenais, a fosseta proboscidal é rasa como na maioria dos Nymphalidae, alojando o lábio no centro e as maxilas lateralmente; área paraocular mais estreita acima da pós-gena (Fig. 8).

Em vista posterior, a projeção do vértice apresenta-se com 0,87 mm de largura e 0,2 mm de altura; a maior área é constituída pela pós-gena com dois níveis de esclerotinização, menos acentuada nas áreas próximas ao forame occipital. Este é bissectado pela ponte pós-occipital, a porção superior tem a forma triangular com a base inferior trilobada e delimitado no bordo superior pelo pós-occipício, em forma de um "bumerangue" relativamente estreito. A porção inferior é quadrangular com o bordo ventral formado pelo prolongamento posterior do esclerito labial e similar na altura e largura máximas (Fig. 9). Na extremidade do bordo dorsal da ponte pós-occipital, destacam-se os côndilos occipitais, semicirculares, onde se articulam os escleritos cervicais, logo abaixo e menores na extremidade do bordo inferior estão às fóveas tentoriais posteriores (MAdDEN 1944).

\section{Antenas (Figs 16, 19-21)}

Clavadas, típicas de Papilionoidea, com flagelo variando entre trinta e nove a quarenta e dois flagelomêros, sendo o último reduzido. Estão inseridas nas margens dorso-laterais do esclerito frontoclipeal e sem dimorfismo sexual. Escapo, como um anel largo, articula-se com o alvéolo antenal e dorsalmente com o pedicelo, de forma semelhante, porém menor. Segundo
EHRLICH (1958b), Acraeini apresenta os flagelomêros com uma largura igual a $1 / 2$ daquela do escapo. Assim, como na maioria dos Nymphalidae, no flagelo ocorrem três carenas ventrais nítidas, porém em $A$. melanisans estão localizadas somente entre o oitavo e o trigésimo segundo flagelomêros (Fig. 19). A partir do trigésimo terceiro ocorre uma expansão progressiva na largura, superior à do escapo, e uma diminuição no comprimento dos flagelômeros para a formação da clava e conseqüente transformação das carenas em um par de concavidades esféricas e independentes em cada flagelomêro (Fig. 20). Em análise detalhada do flagelo em MEV, os flagelomêros apresentam microcerdas esparsas que compõem as carenas e escamas apenas nos três primeiros, EHRLICH (1958b) cita a presença de escamas esparsas nas antenas de Acraeini. Tegumento com microprojeções em forma de "pétalas" intercaladas que variam em tamanho, apresentando arranjos concêntricos que macroscopicamente formam as concavidades da antena (Figs 20 e 21). Este arranjo não foi diagnosticado nos demais grupos de Nymphalidae aqui citados.

\section{Labro (Figs 10-12)}

Abaixo da faixa transclipeal, delimitado pela sutura clipeolabral, o labro apresenta-se como um esclerito impar, mediano e esclerotinizado, sendo as estruturas cerdosas triangulares nas laterais as áreas mais desenvolvidas desse esclerito, que formam e sustentam os pilíferos com aproximadamente 25 cerdas cada (Fig. 12), recobrindo anteriormente a porção basal das gáleas. Entre e unindo os pilíferos, o labro apresentase como um pequeno lobo mediano em forma de meia circunferência, e logo abaixo deste, uma estrutura triangular representando a parte externa da epifaringe (Fig. 11).

\section{Maxilas (Figs 8, 14, 19 e 20)}

Palpos maxilares ausentes, cardos pequenos com forma de "meia-lua", sendo o lado posterior côncavo, localizados entre os estipes e as áreas látero-basais do lábio (Fig. 14). Estipes sustentam as gáleas (CASAGRANDE 1979a). Esclerotinizadas e com duas porções, a basal de superfície nitidamente côncava e em contato com o cardo e o lábio, e a distal na forma de um triângulo retângulo com o "ângulo reto" entre a base das gáleas e o rudimento mandibular (Fig. 8). Fossa proboscidial rasa como na maioria dos ninfalídeos (EHrLIcH 1958b); ocupada anteriormente pelas gáleas côncavas no plano sagital e pouco esclerotinizadas ventralmente, formando o canal alimentar por juxtaposição (probóscide). Quando distendidas, as gáleas alcançam até duas vezes a largura máxima da cabeça. Lateralmente apresentam microcerdas esparsas e tegumento ornamentado semelhante a uma malha fina em alto relevo, porém nas extremidades distais o tegumento apresenta microcerdas e látero-internamente sensilas estilocônicas, espatuladas e mais internamente, microprojeções lineares e serreadas com dentes curvos (Figs 19 e 20).

\section{Lábio (Figs 5, 8, 14, 15, 17 e 22)}

Na região mediana basal da fossa proboscidial, entre os estipes, o lábio apresenta-se como um esclerito triangular bem delimitado, porém côncavo; nessa concavidade ocorrem micro- 

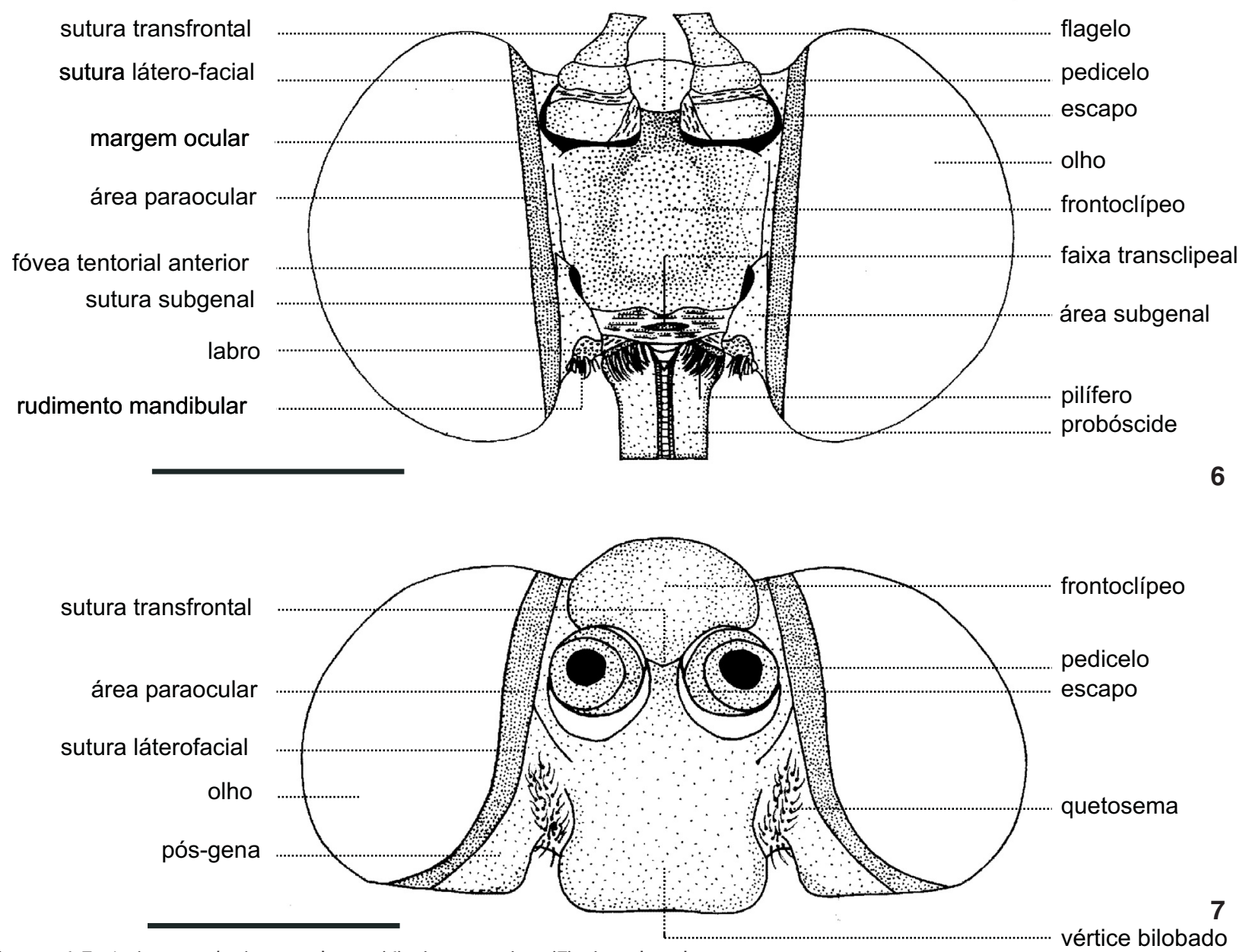

Figuras 6-7. Actinote melanisans, cabeça: (6) vista anterior; (7) vista dorsal.

projeções do tegumento em forma de espinhos (Figs 14-15). Os alvéolos dos palpos labiais presentes logo abaixo dos cardos, estão nas extremidades basais do lábio; o esclerito labial é mais esclerotinizado ao redor do alvéolo dos palpos, tornando-os proeminentes. Lateralmente ao lábio e às maxilas e abaixo do rudimento mandibular, a área hipostomal separa estas estruturas do olho. Palpos labiais triarticulados, cilíndricos e ascendentes, recobertos por escamas dorso-lateralmente, amarelas no artículo basal e no terço basal do artículo médio. O restante com escamas castanho-enegrecidas, porém na superfície látero-ventral o tegumento é recoberto por cerdas enegrecidas, esclerotinizadas e maiores que o comprimento do artículo distal do palpo (Figs 5 e 17). Os dois primeiros artículos com praticamente o mesmo diâmetro, sendo o basal um terço do comprimento do médio. Não identificamos o órgão de vom Rath, segundo HeppNer (1998), uma autapomorfia para Lepidoptera. Mancha sensitiva de Reuter, localizada internamente no artículo basal, látero-dorsalmente e próxima à base da articulação com o alvéolo, é composta por microprojeções espinhosas e espatuladas (Fig. 22).

\section{Região cervical (Fig. 18)}

Membranosa, com exceção de um par de escleritos cervicais inseridos lateralmente. Os escleritos cervicais em Nymphalidae não estão unidos abaixo do cérvix. Em A. melanisans o esclerito cervical é muito similar ao de T. psidii cetoides (BizArro et al. 2003a), com a forma de um " $\mathrm{T}$ " deitado, sendo que a extremidade anterior articula com o côndilo occipital na ponte pós-occipital e a porção superior com a propleura. O órgão cervical é composto por um aglomerado de microcerdas, presentes na parte mediana ventral do esclerito. Unindo a haste superior à região anterior do esclerito, há uma fina membrana, denominada área membranosa do esclerito.

\section{Protórax (Figs 25-27)}

Menor dos três segmentos torácicos articula com a cabeça através do esclerito cervical. Ao contrário de Charaxinae, os Acraeini e demais Nymphalidae, apresentam o parapatágio membranoso (Ehrlich 1958b, C. Mielke et al. 2004b). As projeções laterais do pronoto são fundidas e em vista dorsal formam 

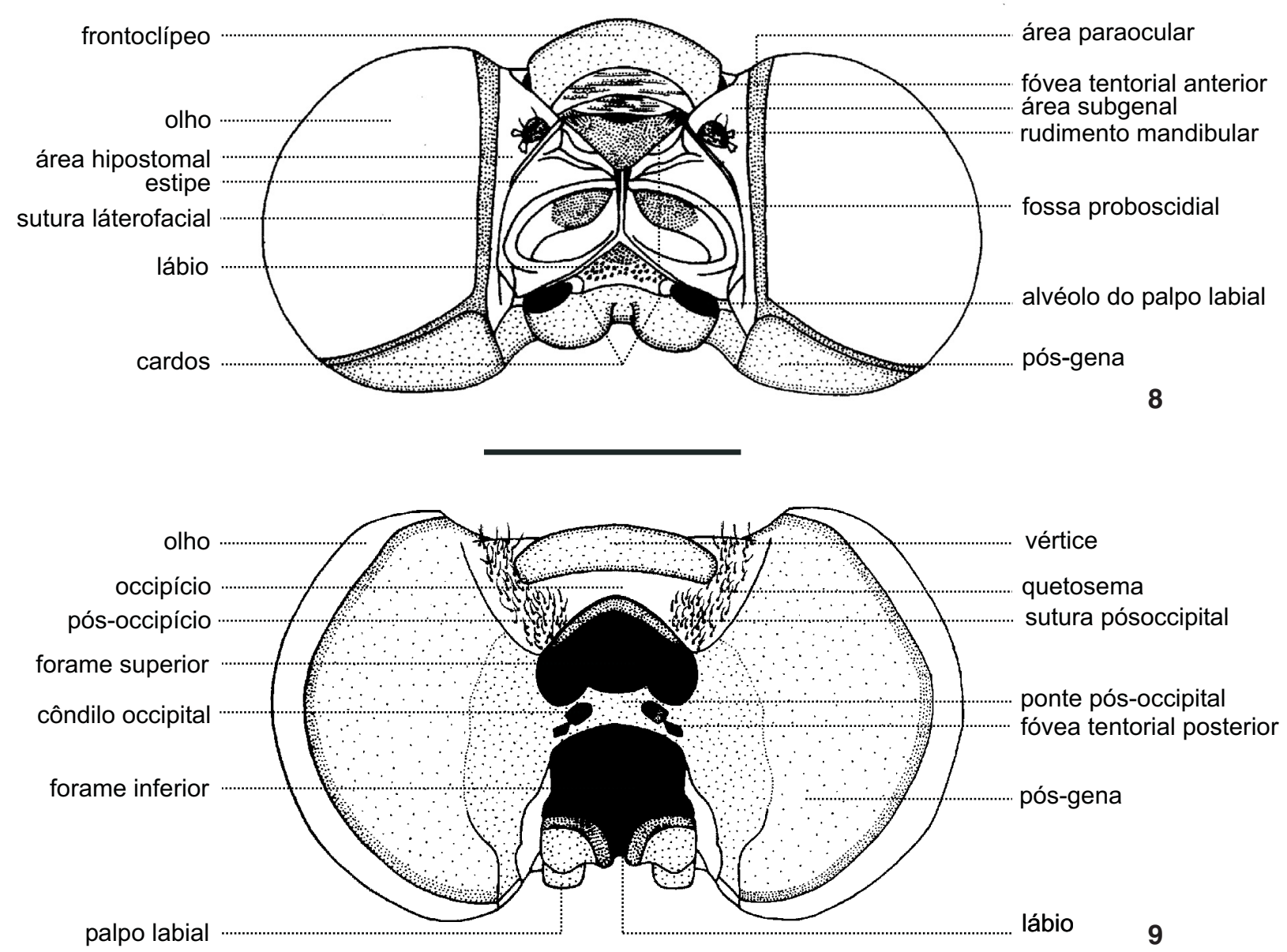

Figuras 8-9. Actinote melanisans, cabeça: (8) vista ventral; (9) vista posterior.

um "Y", onde se inserem anteriormente os patágios. Estes, proeminentes e de aspecto reniforme, possuem a base membranosa sobre as projeções laterais do pronoto. A placa dorsal do pronoto, citata por EHRLICH (1958b) como presente em todas as famílias de Hesperioidea e Papilionoidea (excetuando Pieridae), em $A$. melanisans está fundida com as projeções laterais do pronoto. Marcada por linha sutil e formando um triângulo anterior, lateralmente e abaixo do patágio se torna aparente, articulando com o episterno I acima do bordo dorsal do esclerito cervical. Espiráculo I, delimitado pelo peritrema e em forma de fenda vertical elipsóide, situa-se lateralmente na área membranosa entre o patágio e a tégula. Episterno I articula ântero-dorsalmente com o esclerito cervical e delimita ventralmente juntamente com o trocantim os alvéolos coxais e respectiva articulação pleural da coxa I (Ehrlich 1958a, Casagrande 1979b, Bilotta 1994a, Bizarro et al. 2003b). Pré-esterno I elipsóide, está limitado posteriormente pelo episterno I. A furca I, esclerito em forma de barra estreita e levemente lobada nas extremidades, articula-se anteriormente com o trocantim, formando nessa junção a fóvea furcal, e posteriormente com o espinasterno I. O espinasterno I encontra-se entre o pré-episterno II e o catepisterno II, losangular e alojado junto ao início do discrime II.

\section{Mesotórax (Figs 25-27)}

Maior segmento do tórax. EHrLICH (1958b) e ACKery (1984) relacionam algumas características dos escleritos do mesotórax, como pertencentes à Acraeini e para as quais se faz alguns acréscimos e comparações: a) presença de um pré-episterno mesotorácico com aproximadamente a metade da largura do catepisterno II, apresentando a sutura pré-episternal bem desenvolvida (EHrLich 1958b, ACKERY 1984). Pardopsini, também possui pré-episterno, porém mais estreito, assim como em Caligo beltrao (Illiger, 1801) e nas várias espécies de Morphinae (Casagrande 1979b, Bilotta 1994a, Freitas \& Brown 2004). b) Anepisterno II ausente (Ehrlich 1958b, ACKery 1984), como em T. psidii cetoides (Bizarro et al. 2003b, Freitas \& Brown 2004). c) Tégula muito pequena (EHrLich 1958b, ACKERY 1984). Nesse caso a estrutura foi comparada com os demais Nymphalidae citados nesse estudo, sendo corroborado em A. melanisans. d) Esclerito pós-coxal II curto. Essa estrutura não é visível em $A$. melanisans. 

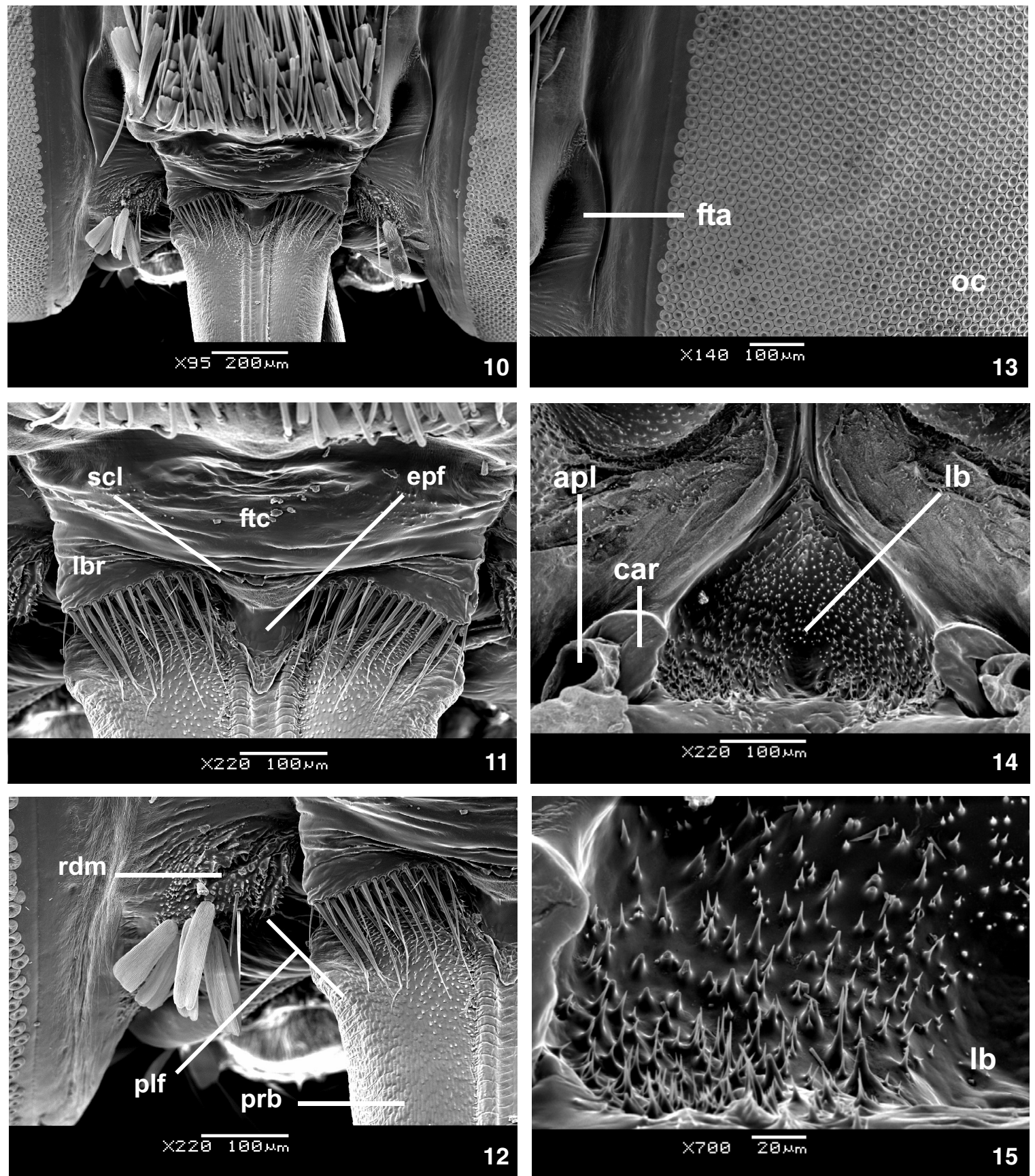

Figuras 10-15. Actinote melanisans, cabeça em MEV: (10-13) vista anterior, peças bucais e olho composto (omatídios); (14-15) vista ventral, peças bucais. (apl) Alvéolo do palpo labial, (car) cardo, (epf) epifaringe, (fta) fóvea tentorial anterior, (ftc) faixa transclipeal, (lb) lábio, (lbr) labro, (oc) olho composto, (plf) pilífero, (prb) probóscide, (rdm) rudimento mandibular, (scl) sutura clípeo-labral.

Dorsalmente o noto II está dividido em prescuto II, escuto II, escutelo II e pós-noto II. Pré-escuto II pequeno e em forma de meia esfera, estreita e com a largura similar à distância entre as extremidades das projeções laterais do pronoto; seus prolonga- mentos laterais passam sob as extremidades do escuto II e atingem a base das tégulas. Delimitando o pré-escuto II e o escuto II está a sutura préscuto-escutal (Matsuda 1970, C. Mielke et al. 2004b). Escuto II é o maior esclerito do tórax, fortemente esclero-

Revista Brasileira de Zoologia 25 (3): 456-478, September, 2008 

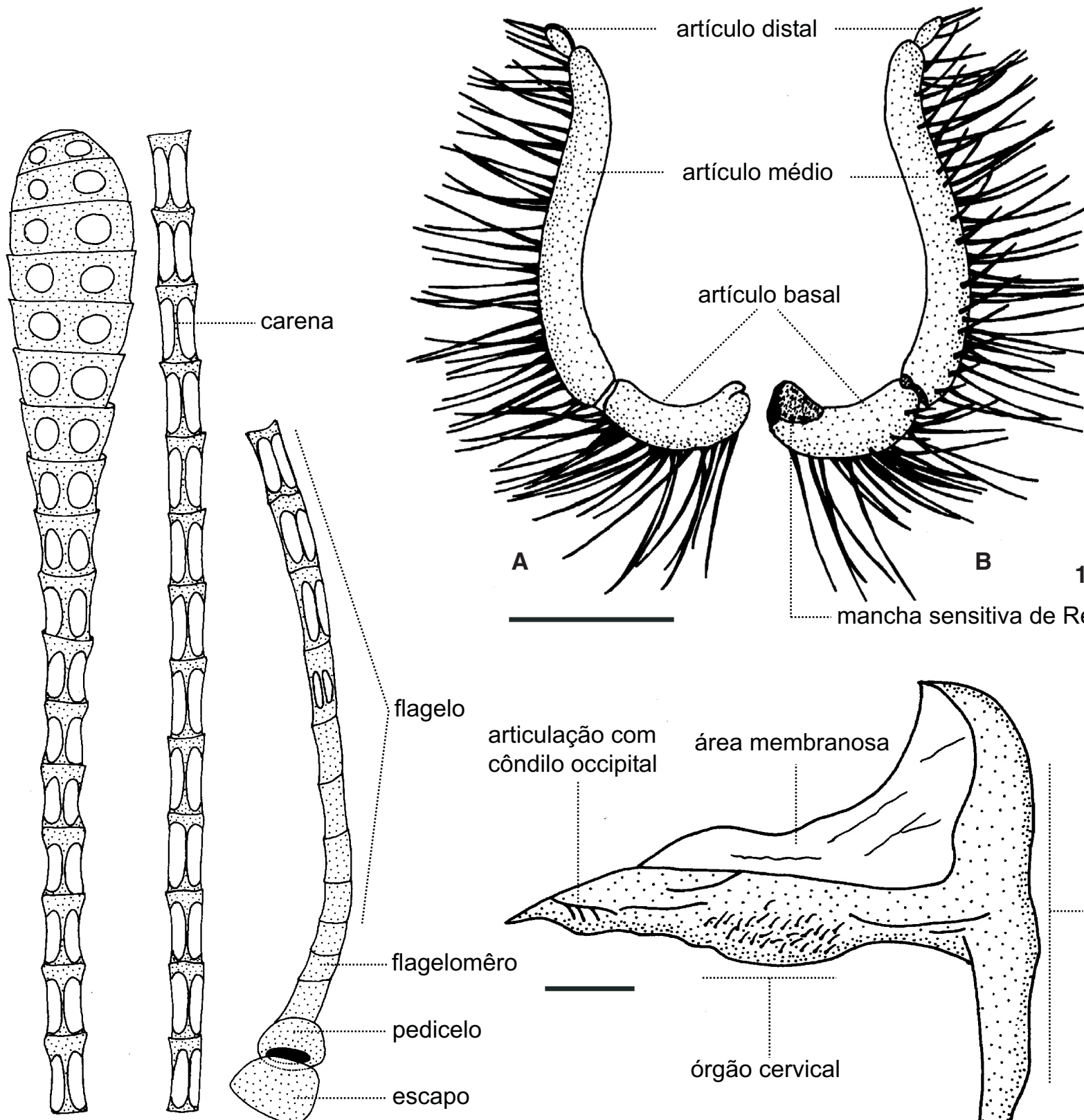

artículo basal
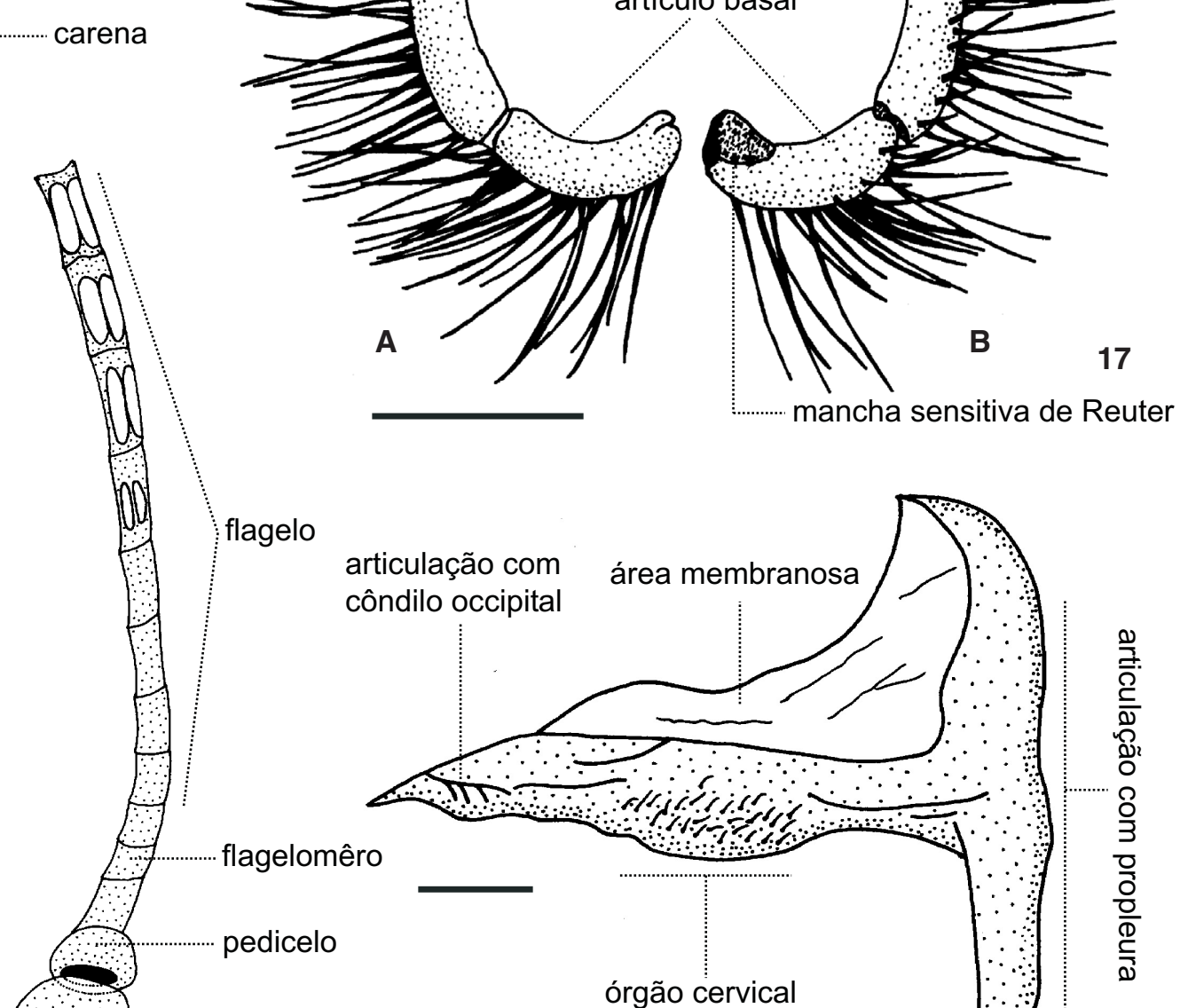

escapo

16

Figuras 16-18. Actinote melanisans: (16) antena, vista ventral; (17) palpo labial, (A) vista lateral externa, (B) vista lateral interna; (18) esclerito cervical, vista lateral externa.

tinizado e achatado lateralmente, formando uma convexidade na superfície dorsal, como uma redoma. Apresenta a forma geral retangular, marcado longitudinalmente pela linha mesoscutal, a extremidade anterior é relativamente reta e com proeminênci- as em forma de acúleos nas laterais. A extremidade posterior é bilobada e em forma de "W", delimitada pela sutura escutoescutelar II; lateralmente a essa sutura e partindo do escutelo II, está o processo notal posterior II em gancho voltado para região 

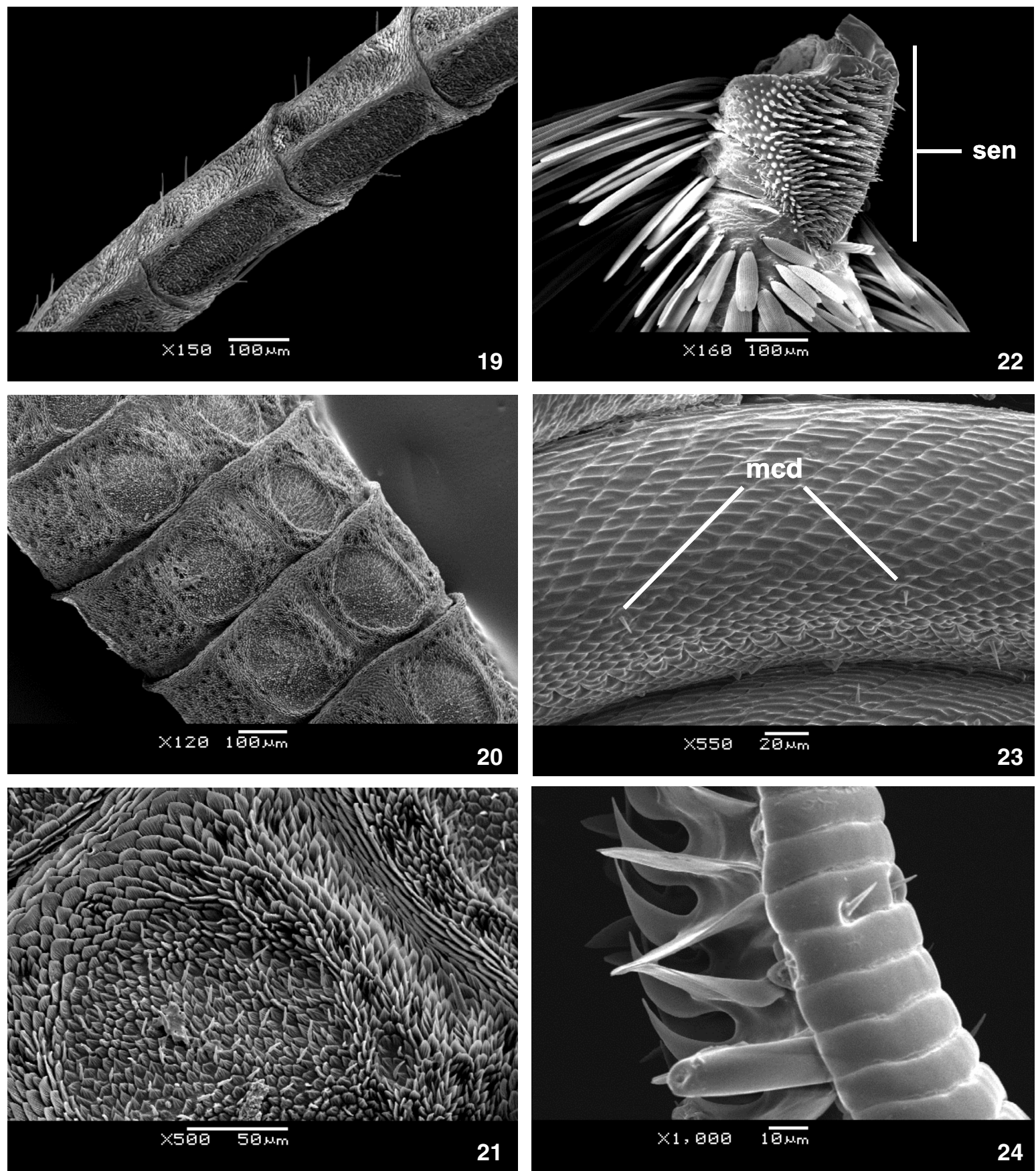

Figuras 19-24. Actinote melanisans: cabeça em MEV: (19) antena, porção proximal; (20) antena, porção mediana da clava; (21) ultraestruturas da antena; (22) palpo labial, artículo basal, vista lateral interna; (23) probóscide, detalhe da parede lateral externa; (24) probóscide, detalhe dos microprocessos (cilíndricos, espatulados, serrilhado e microcerdas). (mcd) Microcerdas, (sen) mancha sensitiva de Reuter.

anterior. O suralar II é formado por um processo do escuto II, também em forma de gancho voltado posteriormente e visível dorsalmente. Escutelo II é o segundo maior esclerito do tórax, acompanha a largura do escuto II, dorsalmente losangular e bem separado do escuto II, devido à profundidade da sutura escutoescutelar II. Pós-noto II visível dorsal e lateralmente, tem a forma de um "V" com largura similar à do prescuto II. Assim como em T. psidii cetoides (BizArro et al. 2003b), o pós-noto II funde-se

Revista Brasileira de Zoologia 25 (3): 456-478, September, 2008 
lateralmente com a porção pós-alar do epimero II. Mesopleura com três escleritos definidos: o pré-episterno II como um triângulo isósceles delimitado pela sutura pré-episternal e medindo aproximadamente a metade da largura do catepisterno II, este elipsóide e não delimitado transversalmente pela sutura pré-coxal II (Ehrlich 1958a, Casagrande 1979b, Bilotta 1994a, Bizarro et al. 2003b, C. MielKe et al. 2004b) ou pela sutura esternopleural (BROCK 1971) para formação do basisterno II (Madden 1944, C. Mielke et al. 2004b) ou esternopleurito II (EHRLICH 1958a) como em C. beltrao, as espécies sul-brasileiras de Morphinae, $Z$. itys itylus e $A$. claudina annetta (Casagrande 1979b, Bilotta 1994a, C. Mielke et al. 2004b). O epimero II é retangular, seus quatro ângulos são ressaltados em forma de bicos, porção pós-alar (EHRLICH 1958a, Casagrande 1979b, Bilotta 1994a, Bizarro et al. 2003b) ou ponte pós-alar (Matsuda 1970, C. Mielke et al. 2004b) fusionada com o pós-noto II. Separando o epimero II do catepisterno II, a sutura pleural II é bem marcada. Pré-epimero II ausente. Ventral ao catepisterno II e ao epimero II e delimitado inferiormente pela sutura marginopleural II, o basisterno II apresenta forma de barra estreita e sinuosa. Posterior ao epimero II, na área membranosa e abaixo do anepisterno III, encontra-se o espiráculo II similar ao da propleura, tanto em forma quanto em tamanho.

Basalar II, formado por duas placas, uma anterior e outra posterior, com aspecto reniforme e de comprimento aproximado ao do espiráculo da propleura, fica encoberto pela tégula. Subalar II, na área membranosa da mesopleura, acompanha a concavidade superior do epimero II entre este e o escuto II. Processo adnotal II, uma estreita barra dorsal ao subalar II que ocupa a porção pós-alar do epimero II juntamente com o processo notal posterior da asa II, pela placa pós-alar e corda axilar. Discrime II, formado pela junção dos catepisternos II, juntamente com o epimero II contornam os alvéolos coxais. Estes, delimitados lateralmente pela sutura pleural II e inferiormente pela sutura marginopleural II. Fóvea apofisial II, losangular, posterior ao discrime II. Lateral ne contígua a esta, a articulação ventral da coxalI.

\section{Metatórax (Figs 25-27)}

Dorsalmente o noto III está dividido em escuto III, escutelo III e pós-noto III. Escuto III articula anteriormente com o pós-noto II, como dois grandes lóbulos triangulares unidos anteriormente por uma estreita ponte esclerotinizada $;$ As porções anteriores são proeminentes e formam os processos notais anteriores III. Delimitado pela sutura escuto-escutelar III, relativamente profunda, o escutelo III apresenta a forma triangular, entre os lóbulos posteriores do escuto III. Processo notal posterior III, projeta-se do bordo posterior do escutelo III, em forma de gancho, voltado anteriormente porém menor e mais aberto que aquele do mesotórax. Pós-noto III menor que o escutelo III, como uma barra estreita e transversa que lateralmente se funde à porção distal do epimero III. Metapleura dividida pela sutura pleural III em episterno e epimero, o episterno com catepisterno III e anepisterno III. Catepisterno III anterior, elipsóide, apresentando inferiormente um pequeno esclerito, uma barra estreita em forma de foice, limitado lateralmente pela sutura pleural III e ventralmente pela sutura marginopleural III. Esse esclerito é semelhante ao que ocorre em $Z$. itys itylus e A. claudina annetta (C. MielKe et al. 2004b) denominado basisterno III. Anepisterno III de forma isolada, com o dobro do tamanho do espiráculo II, elipsóide e com cerdas voltadas posteriormente. A presença destas cerdas não é um caráter exclusivo de Acraeini podendo estar presente em outros grupos de Nymphalidae, assim como já considerou BizArRo et al. (2003b) ao diagnosticá-las no anepisterno III de T. psidii cetoides. Subalar III reduzido, em área membranosa, acima do epimero III, de forma e tamanho similares ao anepisterno III. Acima do subalar III está o processo notal posterior III, com a corda axilar projetando-se das laterais posteriores do escutelo III. Os catepisternos III unem-se ventralmente por uma sutura, o discrime III, e projetam-se posteriormente ao mero III, formando os alvéolos das coxas III. Na região mediana entre os alvéolos coxais está a articulação ventral da coxa III. Entre a sutura marginopleural III e ladeado pelas suturas pleurais III está o basisterno III (C. Mielke et al. 2004b), que ventralmente tem a forma de uma barra estreita. Espinasterno III ausente, como também observado em T. psidii cetoides por BizArRo et al. (2003b).

\section{Coloração do tórax}

Castanho-escuro. Protórax com escamas amarelas, formando uma mancha esférica sobre as laterais externas dos patágios e no episterno I. Esta mancha amarela também está presente nos meso e metatórax, nas áreas basais dos catepisternos II e III, meros II e III, tégulas e área membranosa dos subalares II e III. Esse padrão é mantido entre todas as espécies de Actinote citadas na metodologia.

\section{Asa anterior (Fig. 28)}

Nos Acraeini neotropicais, as asas anteriores possuem a célula discal fechada, o eixo ântero-posterior apresenta $2 / 3$ do comprimento total da margem costal (base até ápice de $\mathrm{R}_{4}$ ) e a margem interna reta, conferindo aspecto subtriangular à mesma. Comparando a venação com outros Nymphalidae citados nesse estudo, difere apenas de T. psidii cetoides (Bizarro et al. 2003b) e Danainae (ACKERY \& VANE-Wright 1984) pela ausência da veia disco-celular superior e a presença de $3 \mathrm{~A}$ vestigial anastomosada com 2A. Venação. Subcosta (Sc): veia mais longa da asa anterior, sofre inflexão progressiva em direção à margem costal onde termina pouco além da origem de $\mathrm{R}_{2}$ (aproximadamente $1 / 3$ antes do comprimento total da margem costal). Rádio (R): com cinco ramos, antes da primeira bifurcação delimita a célula discal anteriormente e segue até a margem costal além do término da subcosta, porém quando atinge aproximadamente a metade do comprimento total da margem costal se ramifica para formar $\mathrm{R}_{1}$, logo adiante $\mathrm{R}_{2}, \mathrm{R}_{3}$, e por fim $\mathrm{R}_{4}$ que termina no ápice da asa e em $\mathrm{R}_{5}$, que constitui a primeira veia da margem externa. Média (M): composta por $\mathrm{M}_{1}, \mathrm{M}_{2}$ e $\mathrm{M}_{3}$, que partem da célula discal paralelamente até a margem externa. Cúbito Anterior (CuA): veia espessa que delimita região inferi- 


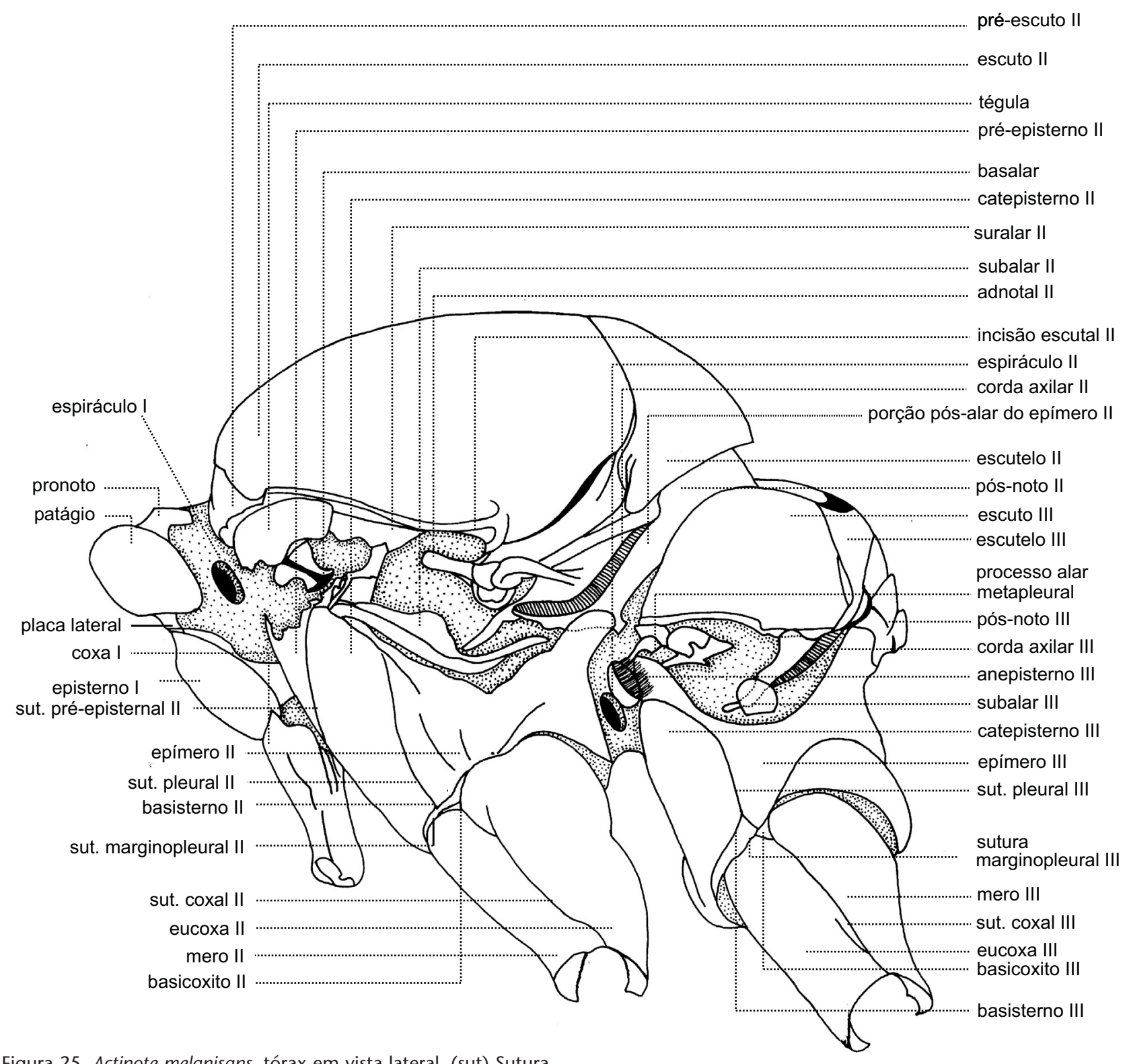

Figura 25. Actinote melanisans, tórax em vista lateral. (sut) Sutura.

or da célula discal, ramificando-se em $\mathrm{CuA}_{1}$ e $\mathrm{CuA}_{2}$ e paralelas até a margem externa da asa. Anal (A): apenas a veia $2 \mathrm{~A}$ está presente, relativamente reta e paralela à margem interna da asa, atingindo a margem externa no ângulo anal. Célula discal fechada por quatro veias transversais tubulares, cujo conjunto forma uma linha sinuosa característica para a tribo Acraeini, são elas: disco-celular superior (dcs), menor das quatro, entre $\mathrm{R}_{\mathrm{s}}-\mathrm{M}_{1}$; disco-celular mediana (dcm), côncava entre $\mathrm{M}_{1}-\mathrm{M}_{2}$; disco-celular inferior (dci), reta e a maior das quatro, entre $\mathrm{M}_{2}-\mathrm{M}_{3}$, e médio-cubital (m-cu), pouco menor que a dci, entre $\mathrm{M}_{3}-\mathrm{CuA}$. $\mathrm{Na}$ face ventral, a membrana alar entre a margem costal e a veia subcostal não é inteiramente revestida por escamas, apenas os $2 / 3$ da porção basal, sendo o restante preenchido por cerdas (Eltringham \& Jordan 1913, PotTs 1943, Paluch et al. 2006). Esse caráter foi confirmado em todas as espécies citadas na metodologia.

\section{Asa posterior (Fig. 29)}

As asas de Actinote são homogêneas interespecificamente quanto à venação, porém um caráter da asa posterior presente em algumas espécies é a ausência da disco-celular superior (dcs) sendo que $\mathrm{R}_{\mathrm{s}}$ e $\mathrm{M}_{1}$ anastomosam-se, variando o tamanho do 


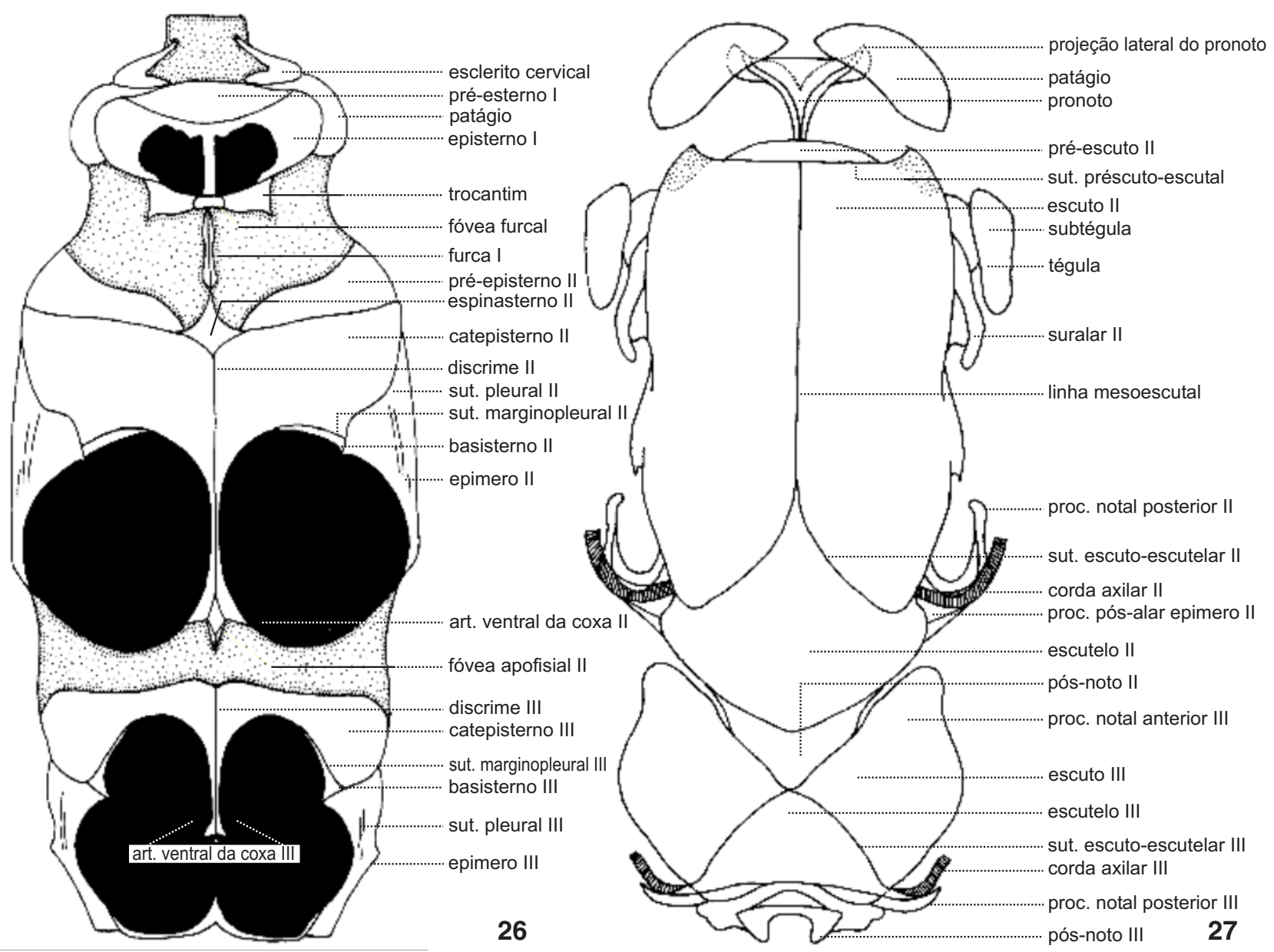

Figuras 26-27. Actinote melanisans, tórax: (26) vista dorsal; (27) vista ventral. (sut) Sutura, (proc) processo, (art) articulação.

tronco (e.g. A. parapheles). Esse caráter pode auxiliar na identificação imediata de táxons semelhantes, como por exemplo, separar A. discrepans de A. melanisans que apresenta nitidamente a veia dcs. Porém, esse caráter pode variar entre presença e ausência em alguns táxons, como $A$. pyrrha. Não foram diagnosticados caracteres de dimorfismo sexual nas asas, excetuando o padrão de coloração e mensurações, sendo as asas da fêmea, na maioria das vezes, maior que as do macho.

Asa posterior subtriangular como a anterior, porém menor e mais arredondada, célula discal fechada por quatro veias transversais. Maior comprimento da asa, entre a base e o ápice da veia $\mathrm{M}_{2}$, pouco superior que a largura, medida entre $\mathrm{Sc}+\mathrm{R}_{1}-$ $2 \mathrm{~A}$, na margem externa. As três primeiras veias se originam do mesmo tronco na base da asa: na porção superior a veia umeral (u) em forma de gancho está voltada para o ápice da asa, ausente na asa anterior e após esta bifurcação o outro braço se continua retilineamente até o ápice da asa. Fusionada com $\mathrm{Sc}+\mathrm{R}_{1}$ na base, abaixo dessa e compondo a parte superior da célula discal o setor radial $\left(\mathrm{R}_{\mathrm{s}}\right)$; estende-se até a margem externa como veia única. Media $(\mathrm{M})$ com os mesmos ramos que na asa anterior, ou sejam, $M_{1}, M_{2}$ e $M_{3}$, que partem da metade posterior da célula discal, paralelamente até a margem externa. Cúbito Anterior (CuA) como na asa anterior, forma a parte inferior da célula discal, com a base livre apesar de próxima da base do tronco superior da célula discal. As veias $\mathrm{CuA}_{1}$ e $\mathrm{CuA}_{2}$, partem da metade posterior da célula discal e seguem paralelas até a margem externa. Três Anais (A) estão presentes. Segundo EHrLIch (1958b), em Nymphalidae duas veias anais estão sempre bem desenvolvidas. Em Actinote logo após a $\mathrm{CuA}_{2}$ em direção a margem externa da asa, a veia $1 \mathrm{~A}$ aparece vestigial, fina e junto à margem externa com $1 / 7$ do comprimento da $2 \mathrm{~A}$, esta possui a base próxima à CuA e é a maior das três, definindo o comprimento da margem interna, a 3A delimita o ângulo anal e é pouco menor, 5/7 de 2A. Célula discal formada superiormente pela $\mathrm{R}_{\mathrm{s}}$ e inferiormente pela $\mathrm{CuA}$ e, como na asa anterior, é fechada pelas veias transversais dcs, dcm, dci e m-cu. Na face ventral apresenta uma fileira de cerdas rígidas alternadas na porção central da célula, entre a base e a região mediana da veia $\mathrm{dcm}$, são as cerdas intradiscais

Revista Brasileira de Zoologia 25 (3): 456-478, September, 2008 
(Eltringham \& Jordan 1913, Potts 1943, Paluch et al. 2006). Este caráter ocorre em ambos os sexos.

\section{Pernas protorácicas (Figs 30, 33-34)}

Actinote melanisans apresenta as pernas e as garras tarsais protorácicas atrofiadas em ambos os sexos. Para as fêmeas de alguns Ithomiinae pequenas garras protorácicas já foram citadas (Ehrlich 1958b). O dimorfismo sexual está nas dimensões maiores e na presença do tarso diferenciado na fêmea. Coxa cilindro-cônica e apendiculada com depressões no tegumento que podem ser confundidas com suturas, articula anteriormente com o episterno I. Trocânter como pequeno esclerito de forma cilíndrica e retangular. Fêmur alongado, glabro, sendo que na fêmea apresenta $4 / 6$ do comprimento da tíbia e tarso juntos. Tíbia nas fêmeas de comprimento similar ao tarso, nos machos é quatro vezes maior. Em ambos os sexos ocorrem apenas cerdas esparsas pelo tegumento e ausência de epífise tibial, assim como nos demais Nymphalidae (EHrLich 1958b) (Fig. 30). Distitarso feminino com sensilas na superfície dorsal (Fig. 33) divididas em duas porções: uma superior elipsoidal e côncava, que apresenta medianamente uma microcerda ladeada por um botão circular convexo (Penz \& PegGIe 2003); a porção inferior, com sensila campaniforme protegida em uma depressão do tegumento (Figs 33 e 34). Na extremidade do distitarso, as garras e as demais estruturas estão ausentes, apenas uma estrutura cilindro-cônica semelhante a uma epífise fortemente esclerotinizada e ladeada por microcerdas está presente (Fig. 33). Esta estrutura também aparece na extremidade do bordo ventral dos tarsômeros anteriores. O tarso do macho é reduzido a um único tarsômero elipsóide com cerdas esparsas.

\section{Pernas Meso e Metatorácicas (Figs 31-32 e 35-40)}

Pernas meso e metatorácicas semelhantes entre si, como também entre os sexos, apresentando dimorfismo apenas nas garras tarsais. As coxas são formadas por dois escleritos unidos medianamente pela sutura coxal; o esclerito anterior, a eucoxa e o posterior, o mero, unidos ao tórax através da sutura marginopleural II e III que é fusionada com o pós-noto II (MADDEN 1944, Ehrlich 1958a, Casagrande 1979b, Bilotta 1994a, Scoble 1995, Bizarro et al. 2003b, C. MielKe et al. 2004b). Acraeinae sensu EhrLich (1958b) é citado como tendo a forma do mero variável, representado por Acraea, Actinote e Bematistes (citado como Planema) (Acraeini) e Pardopsis (Pardopsini), porém, para $A$. melanisans e as demais espécies do gênero, o mero se mantêm constante e de forma triangular, sendo um caráter de Actinote e possivelmente dos demais gêneros neotropicais, Altinote e Abananote (LAmAs 2004b). No ápice das suturas coxais II e III, entre a eucoxa e o mero e abaixo do epimero, está presente um esclerito triangular, o basicoxito II e III, respectivamente no meso e metatórax (Ehrlich 1958a, Casagrande 1979b, C. Mielke et al. 2004b). Distalmente, as coxas, através de uma pequena projeção ou apófise, articulam-se com os trocânteres, de forma cilindro-retangular e comprimento similar ao do distitarso (excetuando o pré-tarso). Este pequeno esclerito une a coxa ao fêmur alongado, cilíndrico, levemente abaulado na superfície medio-ventral e de tegumento liso. Possui comprimento similar à tíbia na perna metatorácica e maior na mesotorácica. Tíbias cilíndricas, ornamentadas por cerdas rígidas espalhadas dorso-lateralmente e ventralmente formam linhas. Apresentam um par de esporões tibiais distais rígidos no bordo ventral (Figs 31 e 32), articulando-se distalmente com o tarso. Tarsos compostos por cinco tarsômeros, o basal e o distitarso são os maiores e com tamanhos similares, da mesma forma os três medianos são similares. Os quatro primeiros com ornamentações iguais às da tíbia, com cerdas rígidas e um par de esporões no bordo ventral, como um todo, possui comprimento similar ao da tíbia. Tanto o macho quanto a fêmea de A. melanisans (Figs 35 e 36) foram estudados comparativamente com A. m. mitama (Figs 39 e 40) em MEV para esses caracteres, sendo que as garras tarsais do macho de $A$. melanisans apresentam a forma de ganchos assimétricos sem sulcos laterais, também presente em muitos Acraea e Bematistes (Pierre 1985a, 1987), ou seja, a garra interna é menor no tamanho e na largura e mais curva que a externa, ambas possuem lóbulos basais. Em ambos os sexos, em MEV, o tegumento da parede basal da garra lateral ao lóbulo é formado por microprojeções em forma de escamas sobrepostas que se tornam retilíneas ao compor os ganchos da garra tarsal (Fig. 37). No grupo mamita, aqui representado por A. m. mitama, as garras não apresentam dimorfismo sexual, são praticamente iguais, entretanto, com a garra interna sutilmente menor, porém, a forma é mantida, confirmando JoRDAN (1913) (Figs 39 e 40). No prétarso de ambos os grupos de espécies, o arólio e o pulvilo são ausentes, apenas o empódio está presente de forma reduzida e bilobado. Em MEV, é possível notar microprojeções com forma de espinhos por todo o tegumento do empódio (Fig. 38).

\section{Abdome (Figs 41 e 42)}

Similares no comprimento e mais estreito nos machos. Em ambos os sexos o abdome é tipicamente alongado. Dois últimos segmentos no macho e os três últimos na fêmea são modificados para formação da genitália; resultando oito segmentos visíveis no macho e sete na fêmea. Espiráculos de forma elipsóide, do primeiro ao sétimo segmento e próximos ao bordo láteroventral dos tergos. Os escleritos abdominais (tergos e esternos) podem ser considerados como relativamente grandes e bem esclerotinizados, uma característica primitiva de Papilionoidea segundo EHrLich (1958b). Primeiro segmento abdominal menor e modificado para articulação com o metatórax. Tergo I com a margem posterior levemente ressaltada e projetada sobre o tergo II, esterno I reduzido e no mesmo plano do esterno II. Abaixo do tergo I, a barra tergo-pleural é projetada e afilada anteriormente, contornando dorsalmente o espiráculo I, na região posterior se dilata, chegando a emparelhar no esterno I (fêmea) e formando a barra pós-espiracular. Anterior ao esterno I, a barra pré-espiracular é estreita lateralmente e une com a projeção anterior da barra tergo-pleural. Alojado na pleura superiormente à barra está o espiráculo I. Em A. melanisans, o esterno I é uma estreita barra

Revista Brasileira de Zoologia 25 (3): 456-478, September, 2008 

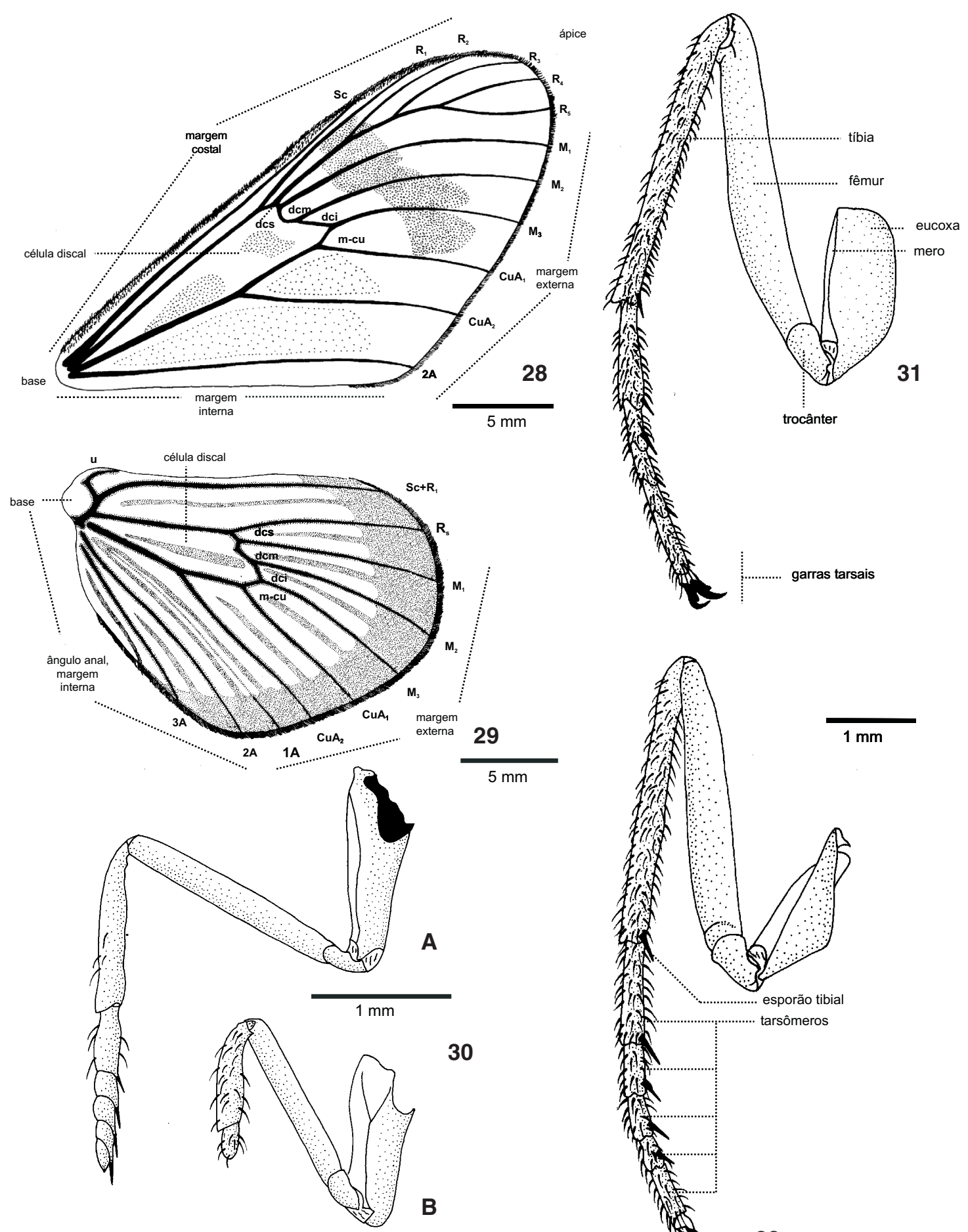

1.

N.

(1)

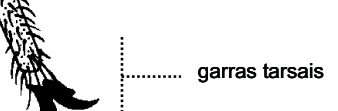

1 ....... garras tarsais

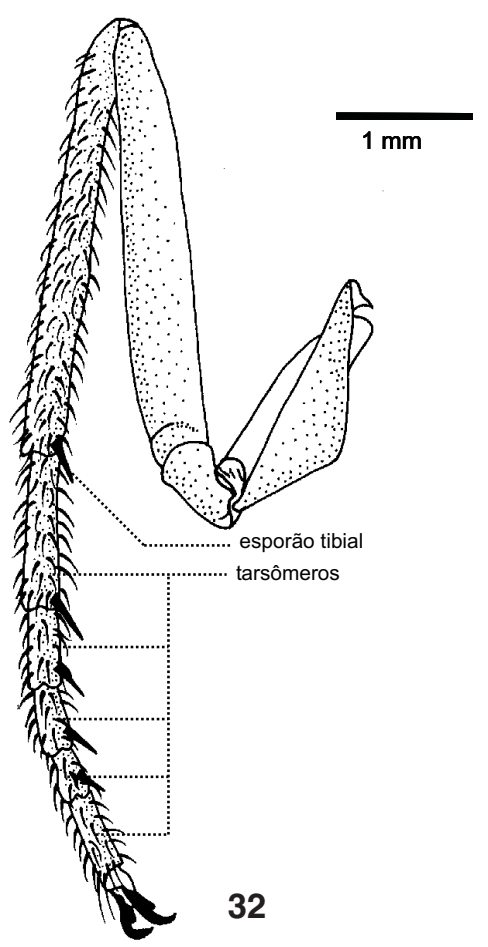

Figuras 28-32. Actinote melanisans, apêndices do tórax: (28) asa anterior; (29) asa posterior; (30) pernas protorácicas em vista lateral "A" fêmea e "B" macho; (31) perna mesotorácica em vista lateral; (32) perna metatorácica em vista lateral. 

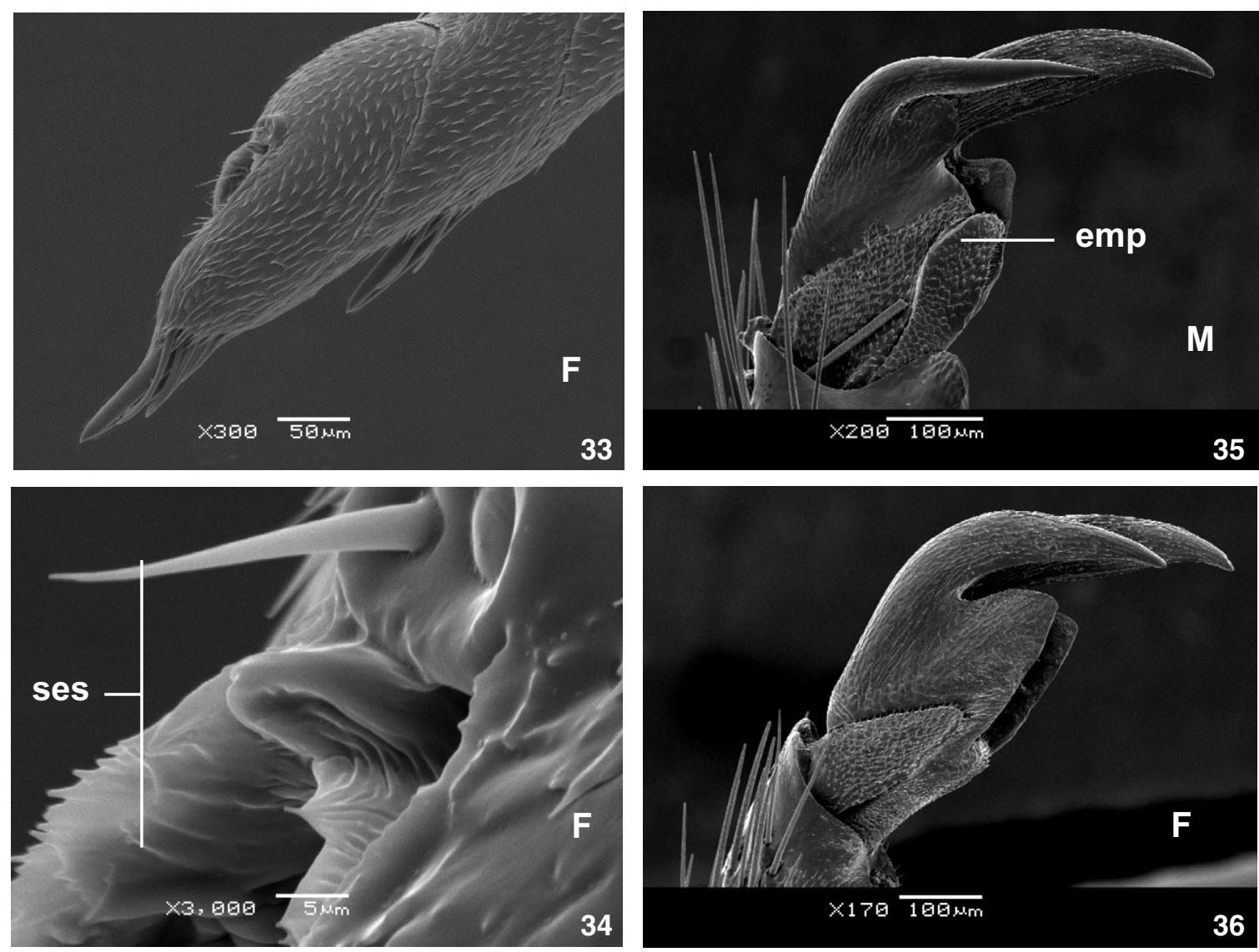

Figuras 33-36. Actinote melanisans, pernas em MEV: (33) distitarso protorácico; (34) detalhe das estruturas sensitivas do distitarso; (35) garra tarsal mesotorácica; (36) garra tarsal mesotorácica. (F) Fêmea, (M) macho, (ses) sensila, (emp) empódio.

esclerotinizada bem definida e com nítida delimitação com o esterno II, não sendo completamente fusionada, porém não há uma articulação intersegmentar. O esterno II tem comprimento maior que o do respectivo tergo, as projeções anteriores formam lobos lateralmente e encaixam no esterno I, abaixo da barra tergopleural; os demais tergos e esternos são simétricos e proporcionais entre si, decrescendo posteriormente de forma sutil. Ressaltado em vista dorsal e ventral, a fêmea de A. melanisans assim como as demais espécies do gênero, apresentam na área dorsolateral e próximo à margem anterior do tergo VIII, um lobo cônico proeminente (Figs 42 e 47). Castanho-enegrecido com pontos amarelos látero-dorsais entre os tergos II-VII; lateralmente duas linhas amarelas uma pontilhada na área terminal dos tergos e a outra continua na área da pleura. Ventralmente linha amarela na região central dos esternos. Esse padrão de coloração foi constante para todas as espécies citadas na metodologia.

\section{Genitália masculina (Figs 43-46)}

Assim como os demais representantes de Papilionoidea, A. melanisans apresenta o nono tergo modificado para formar o tegume esclerotinizado, característica apomórfica da super- família (EHrLich 1958b), em forma de um "V" invertido, cujas extremidades estão projetadas látero-ventralmente, formando os braços do tegume que em vista lateral apresentam-se como barras estreitas. Na união do oitavo tergo e do tegume, a membrana intersegmentar 8-9 invagina e forma uma bolsa onde se inserem as escamas formadoras do tampão genital. Essa estrutura apresenta importante peso taxonômico para diagnosticar algumas espécies e foi ilustrada em MEV juntamente com outras seis espécies do sul e sudeste do Brasil por PALuch et al. (2003). Décimo e último tergo compõe o unco, de base arredondada, simples, que se alonga progressivamente e sem processos laterais. Em vista lateral é curvado ventralmente em forma de um gancho. Encontra-se sutilmente separado do tegume por sutura e assim como em T. psidii cetoides, o unco de $A$. melanisans apresenta no bordo dorso-lateral, basal e mediano um aglomerado de cerdas, que varia intraespecificamente quanto ao número e posição. O unco simples está presente em todas as espécies de Actinote, sendo a composição tegume+unco sempre menor que o comprimento da valva. Algumas espécies de Acraea apresentam unco bífido (PIERre 1985b, 1987), considerado um caráter apomórfico de Papilionoidea (ЕHrLıch 1958b).

Revista Brasileira de Zoologia 25 (3): 456-478, September, 2008 

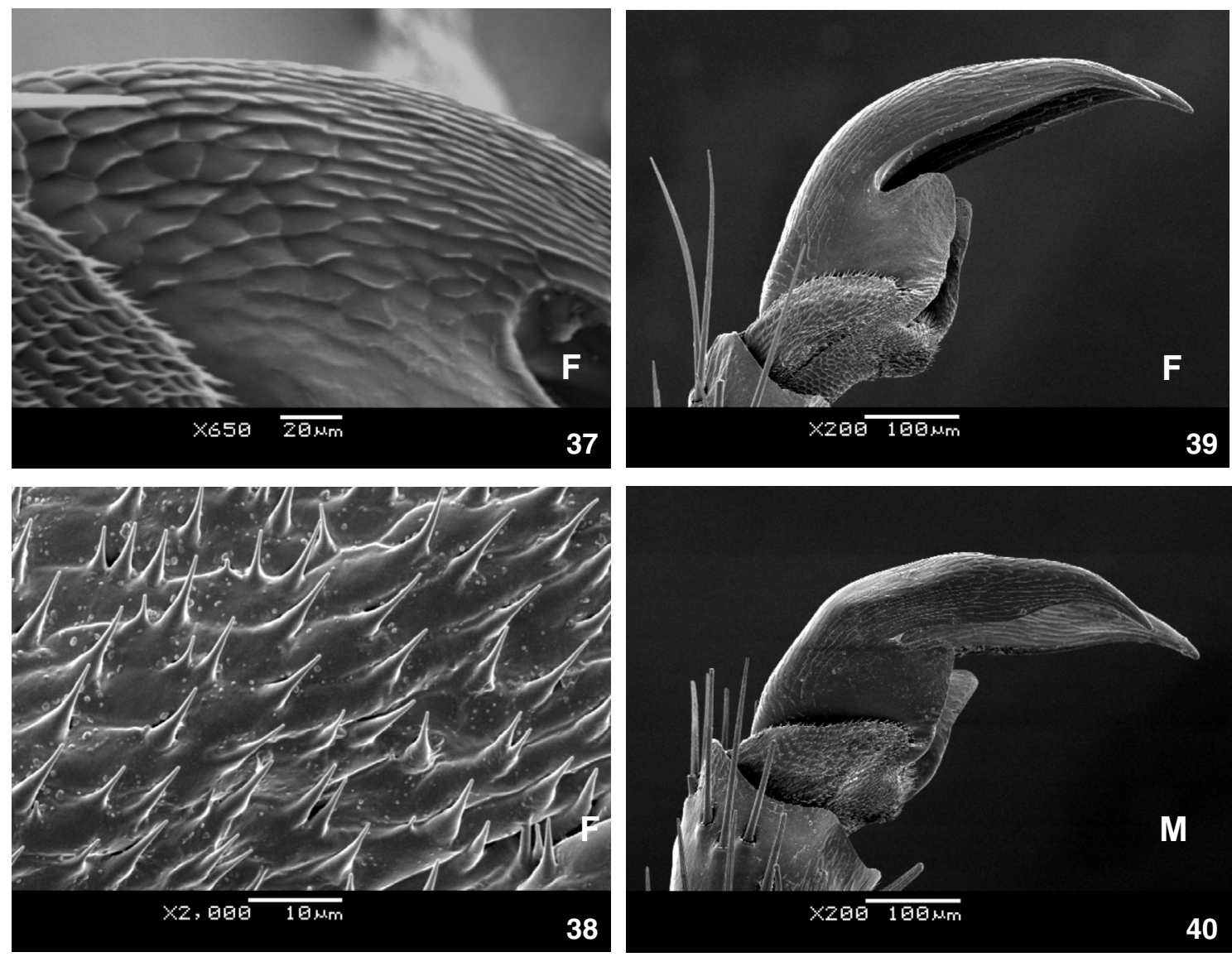

Figuras 37-40. Pernas em MEV: (37) Actinote melanisans, detalhe do tegumento em forma de escamas da garra tarsal; (38) A. melanisans, processos espinhosos do empódio; (39) A. mamita mitama, garra tarsal mesotorácica; (40) A. mamita mitama, garra tarsal mesotorácica. (F) Fêmea, (M) macho.

Conforme Ehrlich (1958b) e ACKery (1984), ao contrário dos demais ninfalídeos, o gnato está ausente em Acraeini. Esta estrutura é responsável pela sustentação do hilo anal, um pequeno orifício no diafragma e sob o unco (CASAgrande 1979c, BIZARRO et al. 2003c). Em A. melanisans o orifício anal é inconspícuo sendo que talvez a ausência do gnato esteja relacionada com esse caráter. Em vista lateral, uma membrana liga todo o braço ventral do tegume com a região mediana do unco, base da região cônica, fundindo-se anteriormente com o diafragma. Abaixo das cerdas presentes na base do unco, podem ocorrer algumas cerdas inseridas nesta membrana, porém com variação intraespecífica. Presença de uma articulação entre os braços ventrais do tegume e os braços dorsais do saco respectivamente (Ehrlich 1958b, Pierre 1987), ou seja, estas estruturas não estão fusionadas, sendo possível diagnosticar claramente onde termina o tegume e inicia-se o saco (Figs 43 e 45). O saco é o nono esterno modificado, seus braços dorsais em A. melanisans apresentam a forma de " $\mathrm{V}$ " desenvolvido, mais longo do que alto, uma sinapomorfia de Acraeini (PIERre 1985b, 1987, Harvey
1991), com uma crista esclerotinizada e proeminente no bordo superior, em vista lateral (Fig. 45). Pierre (1985b, 1987) citou a ausência desta crista assim como das dobras medianas ou transversais nos braços do saco; ANDRADE-C. (1995) também não ilustrou esse caráter nas espécies de Altinote. A projeção anterior do saco é desenvolvida e de aspecto inflado, com a porção anterior arredonda e acompanhando harmonicamente a forma de "V", anterior ao ângulo basal dos braços do saco. Pierre (1985b, 1987) quando se referiu ao saco como maciço, caráter considerado uma sinapomorfia de Acraeini e também aceito por HaRvey (1991), estava na verdade discutindo a projeção anterior do mesmo que, apesar desse aspecto na realidade, é vazio. A porção que compõem o saco propriamente dito, é o bordo ventral localizado entre os braços do saco, composto de um tegumento relativamente espesso. Valvas, segundo Niculescu (1973), são os apêndices do décimo segmento, formadas pela membrana intersegmentar IX-X. Em A. melanisans são simples, simétricas, cilindro-cônicas, recobertas por cerdas, recurvadas dorsalmente e planas lateralmente e com a ponta dilatada, sen-

Revista Brasileira de Zoologia 25 (3): 456-478, September, 2008 

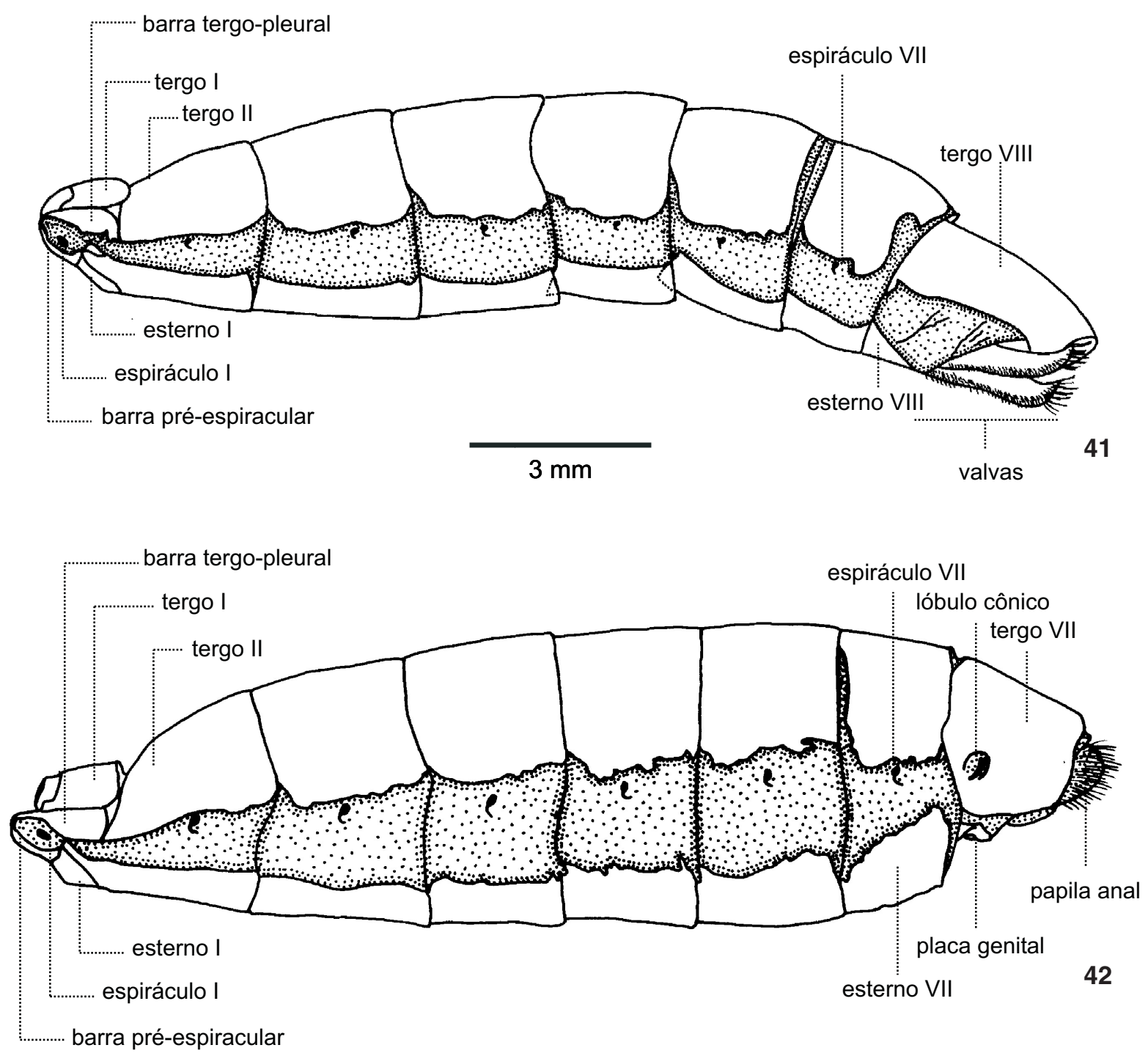

Figuras 41-42. Actinote melanisans, abdome vista lateral: (41) macho; (42) fêmea.

do que o seu comprimento é um pouco menor que o total do comprimento do saco (Pierre 1987). Ocorrem duas articulações laterais e uma dorsal com as valvas; a lateral externa é feita com o braço do saco, este encaixado na concavidade láterobasal da valva através de articulação membranosa; dorsalmente à articulação tegume-saco está ligada através de membranas com a superfície dorso-basal da valva e finalmente uma articulação por justaposição lateral, com uma estrutura subtriangular, a juxta, situada entre a base das valvas que se articula lateralmente com ambas (PIERRE 1985b, 1987). As valvas são recobertas em boa parte por cerdas (Fig. 46), ausentes na superfície dorsolateral externa e na base. Extremidade distal alargada na face lateral interna e relativamente reta, dando o aspecto de uma ponta quadrangular, porém muitas espécies apresentam essa ponta afilada e cônica como em A. genitrix (PALuch et. al. 2003, FRANCINI \& Penz 2006). Em vista ventral as valvas são curvadas para dentro e em vista lateral levemente em direção ao unco. Esses padrões de curvaturas, assim como a largura e o formato da ponta, representam excelentes caracteres para diagnosticar todas as espécies listadas na metodologia (Francini \& Penz 2006, PALUCH et. al. 2006). Em A. melanisans, a juxta em vista ventral, apresenta dois lóbulos na porção superior; um leve estrangulamento mediano nas laterais e afilamento basal, dando o aspecto cordiforme à estrutura; dorsalmente e também visível na face ventral por transparência do tegumento, uma elevação em forquilha cuja base se encaixa na porção basal da juxta e suas extremidades anteriores encerradas no estrangulamento lateral do tegumento. MADDEN (1944) classifica a juxta como pro- 


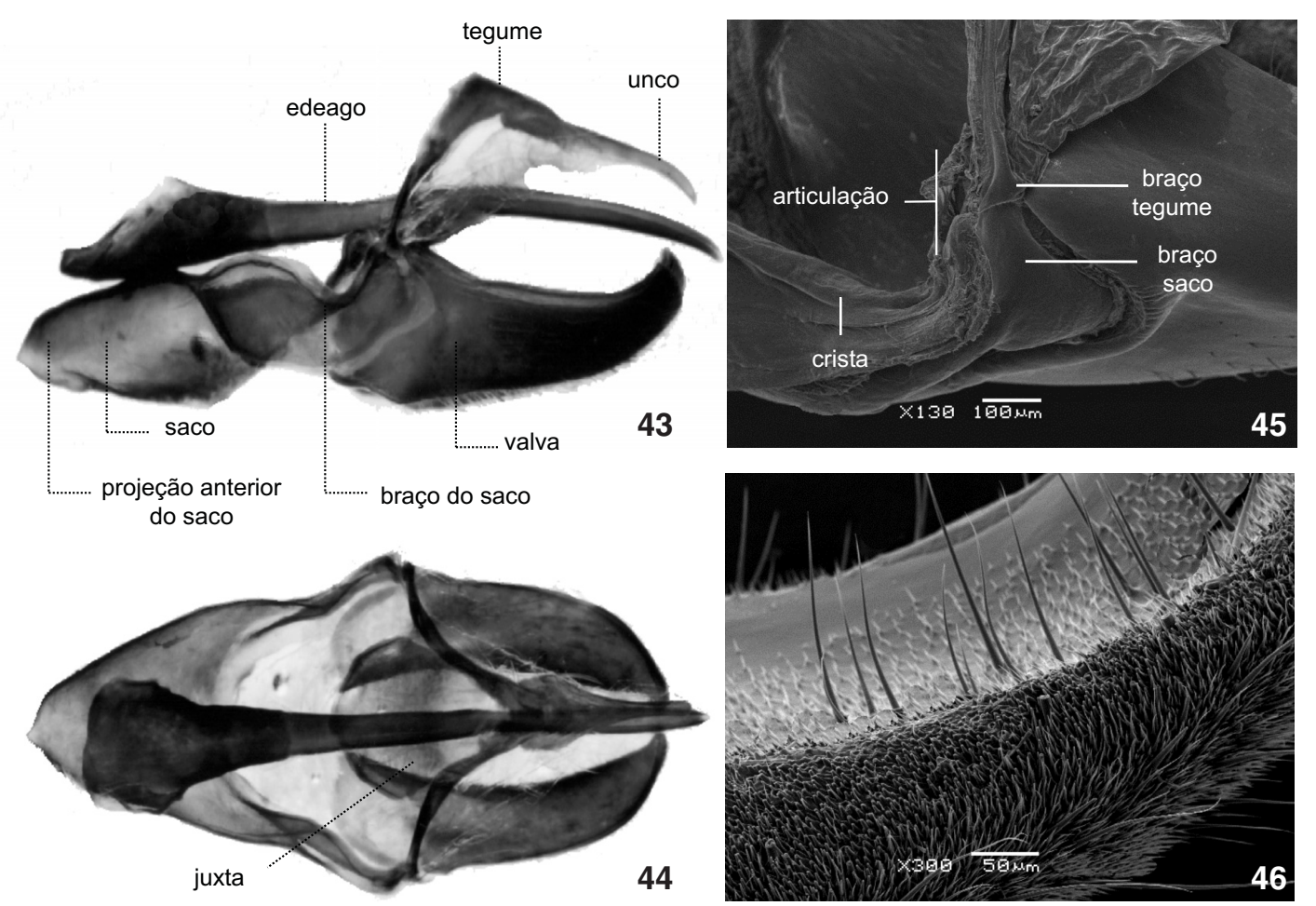

Figuras 43-46. Actinote melanisans, genitália masculina: (43) vista lateral; (44) vista dorsal; (45) detalhe da articulação entre o braço do tegume e o braço do saco em MEV; (46) detalhe da valva em MEV.

vável estrutura de sustentação do pênis, portanto, a forma de forquilha da juxta diagnosticada em praticamente todas as espécies parece ser um caráter exclusivo de Acraeini, que pode servir como local de apoio e alinhamento do pênis. O pênis é constituído pelo duto e bulbo ejaculatórios, edeago e vesica; o bulbo é globoso, aberto anteriormente e transpassado pelo duto ejaculatório; o edeago é a parte esclerotinizada do pênis, cilíndrico, alongado e na região distal com uma abertura por onde everte a vésica membranosa (Oiticica Filho 1946). Actinote melanisans, assim como A. morio apresentam uma das maiores mensurações do edeago entre as espécies de Actinote do sudeste do Brasil (Francini \& Penz 2006, Paluch et al. 2006). A porção anterior em vista dorsal é triangular, lateralmente plana, formando abas; na porção media é sutilmente afilado, a vesica ocupa três oitavos do comprimento total do edeago. Em vista lateral, o edeago é sutilmente curvo. A manica, uma membrana sanfonada, retrátil, que envolve o corpo do edeago, continua-se posteriormente como diafragma membranoso que fecha a porção final do abdome, inserida nas paredes internas do tegume e na borda superior da juxta. O padrão de curvatura, forma da porção anterior, as mensurações de comprimento e diâmetro do edeago, em conjunto com outros caracteres da genitália, são importantes para diagnosticar todas as espécies listadas na metodologia (Francini \& Penz 2006, Paluch et. al. 2006).

\section{Genitália Feminina (Figs 47-50)}

Composta pela modificação dos segmentos abdominais VIII-X, como nos demais representantes de Papilionoidea. Tergos dos segmentos IX ou X formam o par de papilas anais (EHrLICH 1958a). Em A. melanisans as papilas anais são levemente esclerotinizadas, pouco projetadas, e apresentam em vista lateral uma porção externa em forma de meia lua no final do abdome, com numerosas cerdas, e contínua a essa uma porção proximal interna, lisa, com largura similar a da porção distal. Nesta região projetam-se anteriormente no terço superior e lateral, as apófises posteriores, delgadas e com comprimento similar à largura da papila, servindo como local de inserção de músculos. As papilas estão separadas entre si por uma área membranosa em cuja porção superior se encontra o orifício anal e logo abaixo o ovíporo (Figs 48-50). Internamente, sob as apófises anteriores, um par de sáculos membranosos que correspondem às glândulas laterais. Ventral a estas, uma estrutura modificada como um processo levemente esclerotinizado e de largura pouco menor que as apófises posteriores, unem as papilas anais e as glândulas laterais a outra estrutura anterior com tegumento levemente esclerotinizado e com invaginações na parede, composto internamente por um arranjo de microestruturas similares a espículas, a glândula subpapilar, com a mesma altura das papilas, porém com dobro da largura. O oitavo esterno, abaixo da porção posterior da glândula subpapilar é modificado em uma placa densa-

Revista Brasileira de Zoologia 25 (3): 456-478, September, 2008 


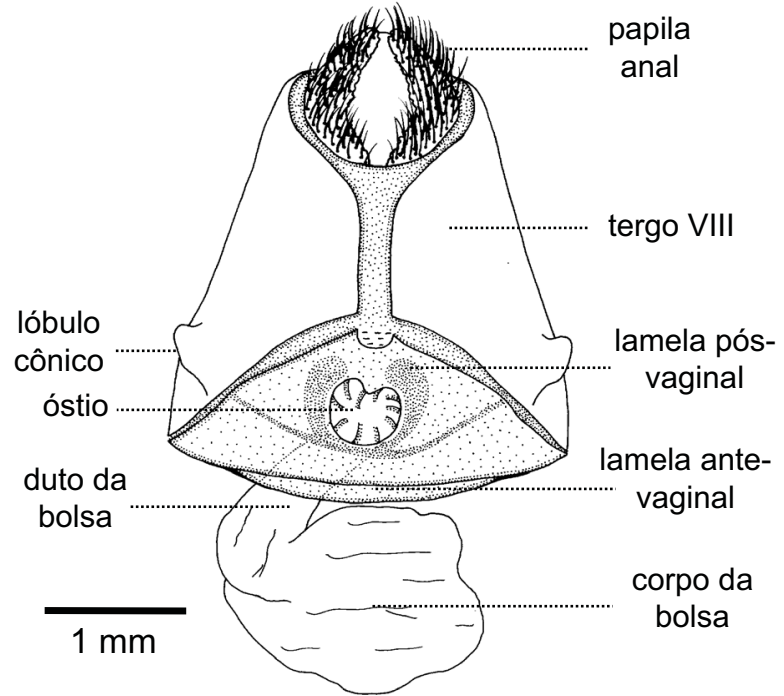

Figura 47. Actinote melanisans, genitália feminina, vista ventral do último segmento abdominal, esterigma e bolsa copuladora.

mente esclerotinizada, retrátil, que quando em posição normal chega a sobrepor internamente um quarto do sétimo segmento. Essa placa genital, ou esterigma, em $A$. melanisans é constituída de lamela ante-vaginal com esclerotinizações circundantes ao óstio da bolsa copuladora, possui forma geral de meia taça, sendo que a lamela pós-vaginal emite duas projeções posteriores em forma de acúleos, enquanto que a lamela ante-vaginal é levemente elevada formando uma aba. Essa forma geral é mantida entre as espécies de Actinote e é considerada sinapomorfia de Acraea (Actinote) segundo Pierre $(1986,1987)$ (Fig. 47). Anteriormente, o duto da bolsa membranoso, de forma tubular, conectase ao corpo da bolsa copuladora sem forma definida, e não ultrapassando o sétimo esterno; sem signos.

\section{DISCUSSÃO}

Segundo o checklist das borboletas Neotropicais (Lamas 2004b), Acraeini compreende três gêneros: Abananote com cinco espécies e nove subespécies; Altinote com quinze espécies e cinquenta e sete subespécies e Actinote com vinte e seis espécies e trinta e seis subespécies descritas. Outras espécies e subespécies foram recentemente descritas, ampliando ainda mais este cenário: Actinote eberti Francini, Freitas \& Penz, 2004; Actinote pratensis Francini, Freitas \& Penz, 2004; Actinote mirnae Paluch \& Mielke, 2006; Actinote mielkei Paluch \& Casagrande, 2006; Actinote furtadoi Paluch, Casagrande \& Mielke, 2006; Actinote morio beckeri Paluch, Casagrande \& Mielke, 2006 e Actinote pellenea giffordi Paluch, Casagrande \& Mielke, 2006.

Apenas para as regiões sul e sudeste do Brasil, há 21 espécies de Actinote, sendo a segunda maior radiação de Nymphalidae nestas regiões, ficando atrás apenas de Adelpha Hübner, [1819] (Limenitidinae: Limenitidini) (WiLLmoтt 2003).

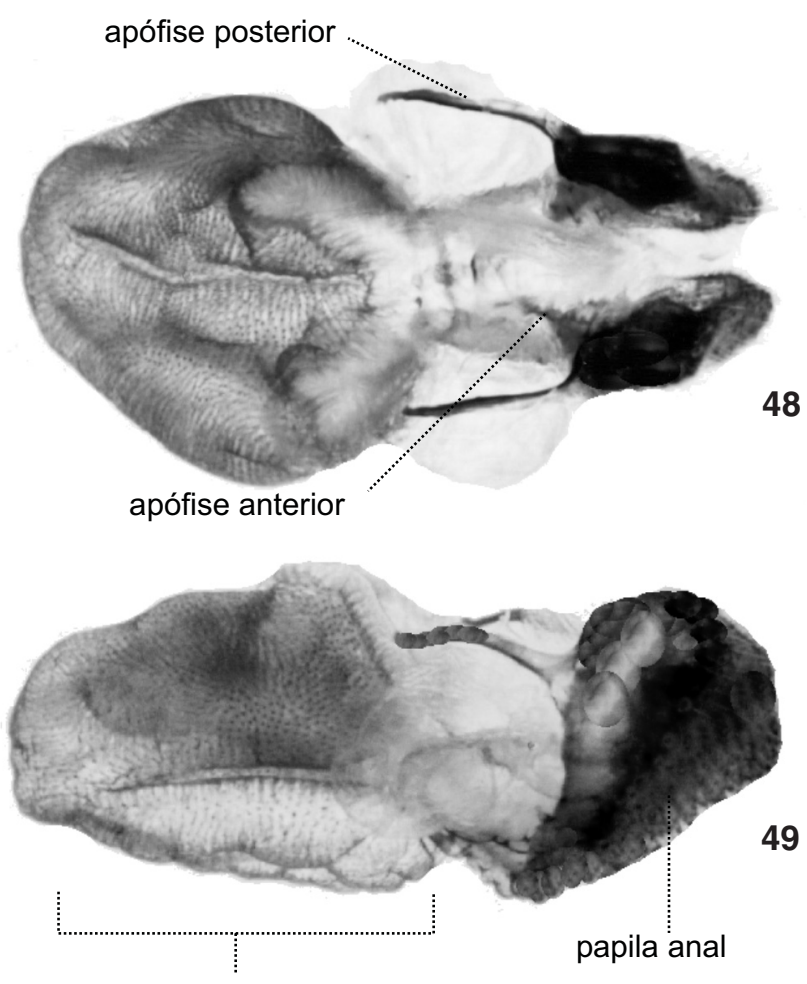

glândula subpapilar

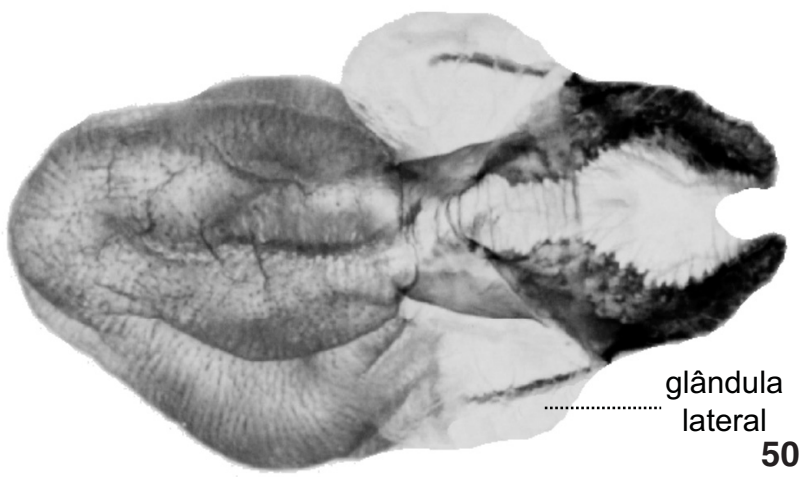

Figuras 48-50. Actinote melanisans, apófises anterior e posterior, papila anal, glândula subpapilar e glândula lateral: (48) vista dorsal; (49) vista lateral; (50) vista ventral.

A monofilia do grupo Acraeini foi testada cladisticamente com dados morfológicos por Pierre (1987), com ênfase nas espécies da região Paleotropical. Segundo a filogenia molecular de Silva-Brandão et al. (2008), as espécies Neotropicais formam um clado com alto suporte de "bootstrap" e "Bremer", corroborando forte evidência de uma única colonização na América do Sul pelo ancestral do clado dos Acraeini Neotropicais.

Até o momento, não há nenhum trabalho detalhando a morfologia de adultos das tribos de Heliconiinae. As únicas referências são para algumas subfamílias e tribos de Nymphalidae (Danainae, Brassolini, Morphini, Ithominae e Charaxinae).

Revista Brasileira de Zoologia 25 (3): 456-478, September, 2008 
Perante este panorama, a maioria das informações morfológicas, quando presentes na literatura, são referentes às genitálias masculinas em suas descrições originais.

Portanto, há possibilidades de alguns caracteres discutidos a seguir, subsidiarem a classificação de Heliconiinae perante Nymphalidae, ou de Acraeini perante Heliconiinae. Salienta-se os seguintes caracteres que poderão ser utilizados em análise filogenética dos possíveis gêneros neotropicais Abananote, Altinote e Actinote.

\section{Cabeça}

EHRLICH (1958b) cita que Nymphalidae pode ou não apresentar pilosidade sobre os olhos. Em A. melanisans e nas demais espécies citadas na metodologia os olhos são glabros.

A presença de uma sutura transfrontal curta entre os alvéolos antenais, também foi diagnosticado em Danaus plexippus (Linnaeus, 1758), T. psidii cetoides e A. claudina annetta (EHrLICH 1958a, Bizarro et al. 2003a, C. Mielke et al. 2004a).

A faixa transclipeal, descrita para D. plexippus (EhrLICH 1958a) e encontrada de forma mais reduzida na largura em $T$. psidii cetoides (BIZArRo et al. 2003a), também foi diagnosticada em A. melanisans, porém, esta estrutura está ausente nos demais Nymphalidae citados neste trabalho.

Em A. melanisans, a área paraocular é similar à de $D$. plexippus, T. psidii cetoides e A. claudina annetta, e ao contrário de C. beltrao (CASAgRANDE 1979a) e em Morpho helenor violaceus Fruhstorfer, 1912; Iphimedeia hercules (Dalman, 1823); Iphixibia anaxibia (Esper, 1801); Cytheritis portis thamyris (Felder \& Felder, 1867); Cytheritis aega (Hübner, 1822); Pessonia catenaria (Perry, 1811); Grasseia menelaus nestira (Hübner, 1821) (Bıьотта 1992), onde as áreas paraoculares são mais estreitas, sendo essa uma estrutura de largura variável como já citado por EHRLıcH (1858b) para Nymphalidae.

Zaretis itys itylus (Charaxinae) apresenta o vértice em vista dorsal levemente bilobado. Em A. melanisans e nas demais espécies do gênero, estes lóbulos são acentuados, formando uma projeção posterior quadrangular e diferenciada dos demais representantes de Nymphalidae aqui citados, talvez como uma característica exclusiva de Acraeini.

Presença de cerdas e escamas no rudimento mandibular como um caráter até então desconhecido dentro dos ninfalídeos.

Lábio com microprojeções do tegumento em forma de espinhos pode estar presente em outros ninfalídeos, porém, é difícil diagnosticá-lo em ampliações inferiores a 700X.

Em D. plexippus, C. beltrao e T. psidii cetoides (EHrLIch 1958a, Casagrande 1979a, Bizarro et al. 2003a), o artículo distal do palpo labial apresenta um terço do comprimento do médio e diâmetro similar. Em A. melanisans e nas demais espécies do gênero citadas em Lamas (2004b), o artículo distal é extremamente reduzido, tanto no diâmetro como no comprimento, sendo até um terço do tamanho das maiores cerdas encontradas no artículo médio. Espécies sul-brasileiras de Morphinae (Bilotta 1992), além de A. claudina annetta e Z. itys itylus (C. MielKe et al. 2004a), apresentam uma similaridade nessa redu- ção, porém ainda são mais proeminentes quando comparados com A. melanisans.

O órgão de vom Rath, que consiste em uma invaginação na porção apical do artículo distal do palpo labial com função sensorial (SCoble 1995), não foi diagnosticado em A. melanisans. Este órgão só é visível após a clarificação da estrutura pelo método de fervura e é possível que sua presença não tenha sido avaliada nas demais espécies do gênero.

A forma geral e a coloração dos palpos labiais de Acraeini são muito típicas e diagnósticos para a tribo, com variações entre os grupos Neotropicais e Paleotropicais. JoRdAN \& Eltringham (1916) consideram que as espécies de Acraea apresentam palpos ocres e inflados. Em Actinote spp. esses são pretos e não inflados e de Bematistes pretos, finos e com uma linha lateral de escamas brancas e densas. Pierre (1987) cita que as características dos palpos labiais possuem valor filogenético, levando em consideração a cor da cutícula e seu revestimento por cerdas e escamas. Para o autor, os representantes neotropicais do subgênero Actinote possuem palpos castanho-enegrecidos. Porém, durante a execução deste trabalho diagnosticou-se a coloração amarela das escamas distribuídas dorso-lateralmente no artículo basal e no terço basal do artículo médio em $A$. melanisans e nas demais espécies citadas na metodologia. É importante testar a validade da possível sinapomorfia para o gênero, quando comparado com as espécies de Altinote e Abananote.

A forma dos forames de $A$. melanisans assemelha-se a de C. beltrao (CASAGRANDE 1979a) e a de algumas espécies sul-brasileiras de Morphinae (BiLotTa 1992). Já em A. claudina annetta e Z. itys itylus (C. MielKe et al. 2004a), a similaridade é com o forame inferior, quadrangular; diferindo de $D$. plexippus e $T$. psidii cetoides (Ehrlich 1958a, BizArro et al. 2003a) nos quais se apresentam retangular e trapezoidal, respectivamente.

\section{Tórax}

A coloração geral do tórax (castanho-enegrecido e ornamentado por escamas amarelas em pontos definidos) forma um padrão constante entre todas as espécies analisadas e, possivelmente, pode representar um caráter diagnóstico para Actinote.

O caráter utilizado por PotTs (1943) para estabelecer os dois gêneros andinos é o mesmo que ELTRINGHAM \& JoRDAN (1913) haviam empregado para formar os seus grupos de espécies. Segundo os autores, em espécies de Actinote, a membrana alar entre a margem costal e a veia subcostal em vista ventral, ao contrário de Abananote e Altinote, não é inteiramente revestida por escamas, apenas os dois terços da porção basal; sendo o restante preenchido por cerdas. O caráter é constante entre todas as espécies de Actinote, restando agora confirmar o seu estado nos demais Acraeini Neotropicais (PAluch et al. 2006).

A presença da veia $1 \mathrm{~A}$ foi utilizada por Jordan \& Eltringham (1916) para separar Actinote de Acraea, sendo que esta veia mesmo rudimentar está completamente ausente no grupo africano. Porém, Pierre (1987) concluiu que esse caráter está presente em outras espécies africanas, como no grupo de espécies denominado "grupo Acraea (Actinote) anacreon", inferindo que 
esse caráter pode ser uma apomorfia de Actinote Neotropicais (sensu stricto) ou uma reversão.

As fêmeas de $A$. melanisans possuem o tarso da perna protorácica composto por cinco tarsômeros, assim como em $C$. beltrao e as espécies sul-brasileiras de Morphinae, A. claudina annetta e Z. itys itylus (CASAgrande 1979b, Bilotta 1994b, C. Mielke et al. 2004b), ao contrário de Danainae e T. psidii cetoides, nas quais ocorre uma redução para três tarsômeros (EHrLICH 1958a, Ackery \& Vane-Wright 1984, Bizarro et al. 2003b).

A presença de um distitarso com sensilas na superfície dorsal da perna protorácica nas fêmeas foi identificado pela primeira vez em $A$. $p$. pellenea e considerado uma das sinapomorfias do subgênero Acraea (Actinote) por Penz \& Peggie (2003). Neste trabalho, os autores corroboraram a classificação de Pierre (1987). Porém, esta análise envolveu uma pequena amostra de espécies, sem incluir representantes de Abananote e Altinote.

EHRLICH (1958b) considera a sutura pré-coxal II como presente nos Nymphalidae. Entretanto, em T. psidii cetoides (BIzArRo et al. 2003b) a sutura pré-coxal II é incompleta e em $A$. melanisans está totalmente ausente, podendo representar um novo caráter para os Acraeini.

JORDAN (1913) considerou as garras tarsais das pernas meso e metatorácicas, juntamente com os caracteres de ornamentação da asa, como excelentes caracteres que distinguem os dois grupos de espécies que ocorrem no Brasil: o grupo thalia e grupo mamita. Segundo EHrLich (1958b) e ACKery (1984), no prétarso das pernas do meso e metatórax ocorrem bons caracteres para o grupo Acraeini como garras tarsais denteadas, assimétricas (macho) com lóbulos basais; arólio e pulvilo reduzidos (ou ausentes) e empódio vestigial. PIerre (1987) considerou os caracteres do prétarso como uma sinapomorfia de Acraeinae, também aceita por HaRvey (1991).

\section{Abdome}

O padrão geral de coloração do tegumento e escamas é similar em todas as espécies de Actinote, podendo ser um caráter exclusivo neste clado. Em Altinote e Abananote, o padrão é geralmente castanho-enegrecido ou em alguns casos bem conspícuos como o vermelho rosado de Altinote neleus neleus (Latreille, [1813]) e Altinote dicaeus dicaeus (Latreille, [1817]).

Nas espécies colombianas de Altinote ilustradas por ANDRADE-C. (1995), o tegume apresenta uma grande expansão na largura dos braços, tornando-o em vista lateral, proeminentemente triangular na porção superior. Em A. melanisans e na maioria das espécies, em vista lateral, os braços apresentam-se como barras estreitas. Porém, algumas espécies ilustradas por FRANCINI \& Penz (2006) se apresentam similares ao grupo andino para este caráter (A. genitrix, A. canutia, A. mamita, A. conspicua e $A$. alalia) e se encontram basais dentro do grupo monofilético de Actinote (sensu stricto) de Silva-Brandão et al. (2008).

Um caráter significativo para Acraeini é a presença de uma articulação entre os braços ventrais do tegume e os braços dorsais do saco respectivamente (Ehrlich 1958b, Pierre 1987), ou seja, estas estruturas não estão fusionadas como em Danai- nae, Brassolinae, Morphinae, Ithomiinae e Charaxinae (EHrLICH 1958a, Casagrande 1979c, Bilotta 1994b, Bizarro et al. 2003c, C. MielKe et al. 2004c), situação em que não é possível diagnosticar claramente onde termina o tegume e inicia-se o saco. Casagrande (1979c) e C. Mielke et al. (2004c) citam as divergências entre os autores em relação aos termos saco e vínculo, e ambos chegam a seguinte conclusão: “...o próprio PIERCE (1914), autor do termo vínculo (vinculum) (Pierce 1909), o sinonimiza com saco (saccus) de Bethune-Baker (1891)".

Quando comparadas lateralmente, as valvas das espécies de Altinote (ilustradas por ANDRADE-C. 1995) apresentam valvas nitidamente mais estreitas do que as de espécies de Actinote (Francini \& Penz 2006, Paluch et al. 2006), com uma acentuada e abrupta curvatura dorsal na região mediana e em direção ao unco, formando um ângulo obtuso de aproximadamente $110^{\circ}$, razão pela qual as valvas nunca ultrapassam o comprimento do unco. Porém, há variações, pois em A. eresia e Altinote hilaris desmiala (Jordan, 1913) a curvatura da valva mostrou-se tênue, com o ápice quase paralelo ao ápice do unco, assemelhando-se à valva de A. melanisans. Silva-BRANDÃo et al. (2008) propuseram três grupos bem definidos dentro do clado Neotropical, com $A$. eresia como um táxon basal irmão de todas as espécies Neotropicais. Nessa análise, A. hilaris desmiala não foi incluída, mas os dados morfológicos podem corroborar a sua inclusão no grupo, atualmente sustentado apenas por $A$. eresia.

Em Acraea, a juxta pode estar ausente, apresentar formas variadas ou estar diferenciada em uma estrutura complexa condutora do edeago (Pierre 1985b, 1987). Nas espécies de Altinote (ANDRADE-C. 1995), a juxta apresenta uma constância interespecífica tanto em tamanho quanto na forma triangular com as extremidades superiores lobadas. Em Actinote, a juxta é muito variável interespecificamente na forma e tamanho, notável quando se compara os padrões extremos entre $A$. eberti e A. melanisans (Francini \& Penz 2006).

O edeago das espécies de Altinote, ilustradas por ANDRADEC. (1995), diferem muito das espécies de Actinote (Francini \& Penz 2006). Porém, apresentam uma constância interespecífica na forma e no tamanho, sendo em vista lateral relativamente reto e curto, dorsalmente largo, porção anterior retangular com metade do comprimento do corpo do edeago, praticamente todo tomado pela vesica, não há afilamento mediano sendo o diâmetro do bulbo e restante do corpo constantes e afilando progressivamente na parte distal. O comprimento total possui a mesma relação encontrada em $A$. melanisans, ou seja, igual ao comprimento total da genitália. A maioria das espécies de Actinote mantém essa mesma relação (Francini \& Penz 2006). Pierre (1987) caracterizou Acraea (Actinote) como tendo edeago muito variável no comprimento, sobretudo a parte cilíndrica mediana cujo diâmetro é constante, jamais se afilando para a extremidade posterior que é pelo menos tão grande quanto o ceco, levemente bilobado e nunca bífido.

A glândula subpapilar e as glândulas laterais constituem uma das sinapomorfias do grupo Acraeini, segundo PierRe (1986,

Revista Brasileira de Zoologia 25 (3): 456-478, September, 2008 
1987). Em conjunto com outros caracteres, a forma e o tamanho das papilas anais e da glândula subpapilar, podem apresentar um possível valor taxonômico para diagnosticar espécies e grupo de subespécies.

Comparativamente aos demais ninfalídeos citados nesse estudo, A. melanisans, como as demais espécies do gênero, apresentam apenas as apófises posteriores proeminentes, como em D. plexippus, T. psidii cetoides, A. claudina annetta e $Z$. itys itylus (Ehrlich 1958a, Bizarro et al. 2003c, C. Mielke et al. 2004c); já em C. beltrao e nas espécies sul-brasileiras de Morphinae (CASAGRANDE 1979c, BiLotTa 1994b) ocorrem os dois pares de apófises de forma proeminente.

\section{AGRADECIMENTOS}

O primeiro autor agradece ao CNPq pela bolsa de doutorado, sendo este estudo parte dos resultados de sua tese de doutoramento junto ao Programa de Pós-graduação em Entomologia, UFPR. Ao laboratório de Microscopia Eletrônica, UFPR, pela colaboração e apoio técnico na realização das análises microscópicas. As figuras 5, 43-44 e 48-50 foram fotografadas por Francisco Santana.

\section{LITERATURA CITADA}

ACKERY, P.R. 1984. Systematic and faunistic studies on butterflies, p. 9-21. In: R.I. VANe-Wright \& P.R. Ackery (Eds). The Biology of Butterflies. London, Academic Press, 429p.

ACKerY, P.R. 1988. Hostplants and classification: a review of nymphalid butterflies. Biological Journal of the Linnean Society 33: 95-203.

ACKERY, P.R. \& R.I. VANE-WRight. 1984. Milkweed butterflies: their cladistics and biology. Being and account of the matural history of the Danainae, a subfamily of the Nymphalidae, Lepidoptera. London, British Museum (Natural History), Comstock Publishing Associates, Cornell University Press, $\mathrm{X}+425 \mathrm{p}$.

Andrade-C., M.G. 1995. Nymphalidae, Acraeinae, Actinote. Monografías de Fauna de Colombia. Bogotá, Universidad Nacional de Colombia,120p.

Bethune-BAKer, G.T. 1891. I. Notes on the genitalia of a gynandromorphous Eronia hippia. Transactions of the Entomological Society of London 1891: 1-6.

BiLotTA, I.G. 1992. Morfologia comparada da cabeça das espécies sul-brasileiras de Morphinae (Lepidoptera, Nymphalidae). Revista Brasileira de Zoologia 9: 261-271.

BiLotTA, I.G. 1994a. Morfologia comparada do tórax das espécies sul-brasileiras de Morphinae (Lepidoptera, Nymphalidae). Revista Brasileira de Zoologia 11: 691-713.

BiLotTA, I.G. 1994b. Morfologia comparada do abdome das espécies sul-brasileiras de Morphinae (Lepidoptera, Nymphalidae). Revista Brasileira de Zoologia 11: 737-748.

Bizarro, J.S.; M.M. Casagrande \& O.H.H. Mielke. 2003a. Morfologia externa de Thyridia psidii cetoides (Rosenberg \& Talbot)
(Lepidoptera, Nymphalidae, Ithomiinae). I. Cabeça e Apêndices. Revista Brasileira de Zoologia 20: 279-284.

Bizarro, J.S.; M.M. Casagrande \& O.H.H. Mielke. 2003b. Morfologia externa de Thyridia psidii cetoides (Rosenberg \& Talbot) (Lepidoptera, Nymphalidae, Ithomiinae). II. Tórax e Apêndices. Revista Brasileira de Zoologia 20: 419-425.

Bizarro, J.S.; M.M. Casagrande \& O.H.H. Mielke. 2003c. Morfologia externa de Thyridia psidii cetoides (Rosenberg \& Talbot) (Lepidoptera, Nymphalidae, Ithomiinae). III. Abdome e Apêndices. Revista Brasileira de Zoologia 20: 681-684.

BRock, J.P. 1971. A contribution towards and understanding of the morphology and phylogeny of the Ditrysian Lepidoptera. Journal of Natural History 5: 29-102.

CASAGRANDE, M.M. 1979a. Sobre Caligo beltrao (Illiger). II: Morfologia externa da cabeça do adulto (Lepidoptera, Satyridae, Brassolinae). Revista Brasileira de Biologia 39: 223-227.

Casagrande, M.M. 1979b. Sobre Caligo beltrao (Illiger). III: Morfologia externa do adulto - tórax (Lepidoptera, Satyridae, Brassolinae). Revista Brasileira de Biologia 39: 347-355.

Casagrande, M.M. 1979c. Sobre Caligo beltrao (Illiger). IV: Morfologia externa do adulto - abdome (Lepidoptera, Satyridae, Brassolinae). Revista Brasileira de Biologia 39: 711-716.

Casagrande, M.M. 2004. Nymphalidae. Morphinae. Tribe Brassolini, p. 201-205. In: G. LAMAS (Ed.). Checklist: Part 4A. Hesperioidea - Papilionoidea, 439p. In: J.B. HePPNER (Ed.). Atlas of Neotropical Lepidoptera, vol. 5A. Gainesville, Association for Tropical Lepidoptera, Scientific Publishers.

Duarte, M.; M.M. Casagrande \& O.H.H. Mielke. 2001. Morfologia externa do adulto de Hemiargus hanno (Stoll) (Lepidoptera, Lycaenidae, Polyommatinae, Polyommatini). I. Cabeça. Revista Brasileira de Zoologia 18: 225-238.

EhrLich, P.R. 1958a. The integumental anatomy of the monarch butterfly Danaus plexippus L. (Lepidoptera - Danaidae). The University of Kansas Science Bulletin 38: 1315-1349.

EHrLICH, P.R. 1958b. The comparative morphology, phylogeny and higher classification of butterflies. The University of Kansas Scientific Bulletin 39: 305-370.

Eltringham, H. \& H.E.K. Jordan. 1913. Nymphalidae: Subfam. Acraeinae. Lepidopterorum Catalogus, vol. 11, 65p.

Francini, R.B. \& C.M. Penz. 2006. An illustrated key to male Actinote from Southeastern Brazil (Lepidoptera, Nymphalidae). Biota Neotropica 6: 1-46.

Francini, R.B.; A.V.L. Freitas \& C.M.Penz. 2004. Two new species of Actinote (Lepidoptera, Nymphalidae) from Southeastern Brasil. Zootaxa 719: 1-10.

Freitas, A.V.L. \& K.S. Brown Jr. 2004. Phylogeny of the Nymphalidae (Lepidoptera). Systematic Biology 53: 363-383.

HaRvey, D.J. 1991. Higher classification of the Nymphalidae, p. 225-273. In: H.F. Nijhout (Ed.). The development and evolution of butterfly wing patterns. Washington, Smithsonian Series Comparative Evolutionary Biology, 297p.

Heppner, J.B. 1998. Classification of Lepidoptera. Part 1. Introduction. Holarctic Lepidoptera 5 (Suppl. 1): I-IV, 1-148. 
JoRdAN, H.E.K 1913. I. Unterfamilie: Acraeinae, p. 358-374. In: A. SeItz (Ed.). Die Gross-Schmetterlinge der Erde. Stuttgart, Alfred Kernen, vol. 5, 1141p.

Jordan, H.E.K. \& H. Eltringham. 1916. Nymphalidae, subfam. Acraeinae. Genera Insectorum 169: 1-81, 2 pls.

LAMAS, G. 1996. Lista comentada de los nombres propuestos para los Acraeini neotropicales, y su material-tipo (Lepidoptera: Nymphalidae, Heliconiinae). Revista Peruana de Entomología 39: 29-48.

Lamas, G. 2004a. Nymphalidae. Morphinae. Tribe Morphini, p. 192-201. In: G. LAMAS (Ed.). Checklist: Part 4A. Hesperioidea - Papilionoidea, 439p. In: J.B. HePpNER (Ed.). Atlas of Neotropical Lepidoptera, vol. 5A. Gainesville, Association for Tropical Lepidoptera, Scientific Publishers.

Lamas, G. 2004b. Heliconiinae, p. 262-274. In: G. Lamas (Ed.). Checklist: Part 4A, Hesperioidea - Papilionoidea, 439p. In: J.B. Heppner (Ed.). Atlas of Neotropical Lepidoptera, vol. 5A. Gainesville, Association for Tropical Lepidoptera, Scientific Publishers.

MadDEn, A.H. 1944. The external morphology the adult tobacco hornworm (Lepidoptera, Sphingidae). Annals of the Entomological Society of America 27: 145-160.

MatsudA, R. 1970. Morphology and evolution of the insect thorax. Memoirs of the American Entomological Institute 4: 431.

Michener, C.D. 1952. The Saturniidae (Lepidoptera) of the Western Hemisphere, morphology, phylogeny, and classification. Bulletin of the American Museum of Natural History 98: 335-502.

Mielke, C.G.C.; O.H.H. Mielke \& M.M. Casagrande. 2004a. Estudo comparado da morfologia externa de Zaretis itys itylus (Westwood) e Agrias claudina annetta (Gray). (Lepidoptera, Nymphalidae, Charaxinae). I. Cabeça e Apêndices. Revista Brasileira de Zoologia 21: 357-369.

Mielke, C.G.C.; O.H.H. Mielke \& M.M. Casagrande. 2004b. Estudo comparado da morfologia externa de Zaretis itys itylus (Westwood) e Agrias claudina annetta (Gray). (Lepidoptera, Nymphalidae, Charaxinae). II. Tórax e Apêndices. Revista Brasileira de Zoologia 21: 421-433.

Mielke, C.G.C.; O.H.H. Mielke \& M.M. Casagrande. 2004c. Estudo comparado da morfologia externa de Zaretis itys itylus (Westwood) e Agrias claudina annetta (Gray) (Lepidoptera, Nymphalidae, Charaxinae). III. Abdome e Apêndices. Revista Brasileira de Zoologia 21: 905-912.

Niculescu, E.V. 1973. L'armure génitale chez les Lépidoptères. Bulletin de la Societé Entomologique de Mulhouse (Suppl.): 1-96.

Oiticica Filho, J. 1946. Sobre a morphologia do pênis em Lepidoptera. Boletim do Museu Nacional, Nova Série, Zoologia, 50: 1-36.

Paluch, M.; M.M. Casagrande \& O.H.H. Mielke. 2003. Tampão genital de Actinote Hübner, como caráter taxonômico. (Lepidoptera, Nymphalidae, Acraeinae). Revista Brasileira de Entomologia 47: 573-580.
Paluch, M.; M.M. Casagrande \& O.H.H. Mielke. 2006. Três espécies e duas subespécies novas de Actinote Hübner (Nymphalidae, Heliconiinae, Acraeini). Revista Brasileira de Zoologia 23: 764-778.

Penz, C.M. \& R.B. Francini. 1996. New species of Actinote Hübner (Nymphalidae: Acraeinae) from Southeastern Brazil. Journal of the Lepidopterists' Society 50: 309-320.

Penz, C.M. \& D. Peggie. 2003. Phylogenetic relationships among Heliconiinae genera based on morphology (Lepidoptera: Nymphalidae). Systematic Entomology 28: 451-479.

Pierce, F.N. 1909. The genitalia of the Noctuidae. Liverpool, A.W. Duncan Printer, 88p.

PIERCE, F.N. 1914. The genitalia of the group Geometridae of the Lepidoptera of the British Islands. Faringdon, Oxon, 84p.

Pierre, J. 1985a. Morphologie des griffes de Acraeinae (Lépidoptères Nymphalides). Comptes Rendus hebdomadaires des Séances de l'Académie des Sciences de Paris (3) 300 (8): 333-336.

Pierre, J. 1985b. Morphologie comparée de l'appareil génital mâle des Acraeinae (Lepidoptera, Nymphalidae). Annales de la Société entomologique de France 21 (4): 381-391.

Pierre, J. 1985c. Les sphragis chez les Acraeinae (Lepidoptera, Nymphalidae). Annales de la Société entomologique de France 21 (4): 393-398.

Pierre, J. 1986. Morphologie comparée de l'appareil genital femelle des Acraeinae (Lepidoptera, Nymphalidae). Annales de la Société entomologique de France 22 (1): 53-65.

Pierre, J. 1987. Sistématique cladistique chez les Acraea (Lepidoptera, Nymphalidae). Annales de la Société entomologique de France 23 (1): 11-27.

PotTs, R.W.L. 1943. Systematic notes concerning American Acraeinae (Lepidoptera: Nymphalidae), Pan-Pacific Entomologist 19 (1): 31-32.

Scoble, M. 1995. The Lepidoptera, form, function and diversity. New York, Natural History Museum Publications, Oxford University Press, 404p.

Silva-Brandão, K.L.; N. Wahlberg; R.B. Francini; A.M.L. AzeredoEspin; K.S. Brown JR; M. Paluch; D.C. Lees \& A.V.L. Freitas. 2008. Phylogenetic relationships of butterflies of the tribe Acraeini (Lepidoptera, Nymphalidae, Heliconiinae) and the evolution of host plant use. Molecular Phylogenetics and Evolution 46: 515-531.

SNODGRASS, R.E. 1935. Principles of insect morphology. New York, McGraw-Hill, 667p.

VAN Son, D. 1963. The butterflies of Southern Africa. Part III. Nymphalidae: Acraeinae. Pretoria, Transvaal Museum, 130p.

Willmott, K.R. 2003. The genus Adelpha: its systematics, biology and biogeography (Lepidoptera: Nymphalidae: Limenitidini). Gainesville, Scientific Publishers, 322p.

Submitted: 24.XI.2007; Accepted: 12.IX.2008.

Editorial responsibility: Walter A.P. Boeger 